\title{
DECOLONIZAR LAS CIENCIAS DE LA EDUCACIÓN: PEDAGOGÍA, ALTERSOFÍA Y HACER EDUCATIVO DECOLONIAL
}

\section{DECOLONIZING EDUCATION SCIENCES: PEDAGOGY, OTHERSOPHY AND DECOLONIAL EDUCATIONAL DO}

\author{
Alexander Ortiz Ocaña ${ }^{1}$ \\ Ana Maloof Díaz \\ Habib Mejía Porto ${ }^{3}$ \\ Universidad del Magdalena \\ Universidad Popular del Cesar
}

\section{ABSTRACT:}

It is urgent to configure new ways of teaching based on the knowledge of the Other, considered inferior, and not only in the modern/colonial pedagogy, considered superior. We suggest decolonizing the educational sciences through Othersophy and Decolonial Educational Do. We assume Othersophy as an "other" way of educating, for the detachment of modern/colo-

\footnotetext{
1 Doctor en Ciencias de la Educación. Docente de planta de la Universidad del Magdalena, Santa Marta, Colombia. aortiz@unimagdalena.edu.co / alexanderortiz5000@ gmail.com / ORCID: http://orcid.org/ 0000-0001-55949422. Scopus Author ID: 57191888741

2 Magíster en Pedagogía. Docente catedrática de la Universidad Popula del Cesar. Colombia. Estudiante del Doctorado en Ciencias de la Educación Rudecolombia y Universidad del Magdalena, Santa Marta, Colombia. gabrielamaloof@gmail.com / ORCID: http://orcid.org/ 0000-0002-0017-7071.

3 Magíster en Educación. Docente catedrático de la Universidad del Magdalena, Colombia. Estudiante del Doctorado en Ciencias de la Educación Rudecolombia y Universidad del Magdalena, Santa Marta, Colombia. habibmejiaporto@gmail.com.
}

nial pedagogy. We analyze for what an "other" didactic. We characterize decolonial educational do as a decolonizing process, to disobey the USA-Eurocentric didactic, through learning actions and traces: communal contemplate, alterative converse and configurational reflect, which characterize the decolonial educational vocation.

\section{KEYWORDS}

Coloniality, decoloniality, education, pedagogy, didactic, learning.

\section{PROEMIO DECOLONIAL}

Las ciencias de la educación están girando desde una perspectiva decolonial, siguiendo los pasos del giro decolonial, que ha impactado con fuerza en su sistema categorial. Es necesario no ignorar las urgencias que nos convocan y las emergencias que nos invitan a la resistencia 
epistemológica, a partir de la desobediencia epistémica. Hoy es un imperativo decolonizar las ciencias de la educación. Esto solo es posible si giramos junto al giro decolonial.

Es necesario hacer una lectura decolonial de la genealogía de las ciencias de la educación. Mirar la pedagogía, el currículo y la didáctica en clave decolonial nos permitirá develar el carácter eurocéntrico del sistema categorial de estas teorías de la educación y la enseñanza. Debemos desoccidentalizar las ciencias de la educación y develar la doctrinalidad de la educación y la formación, el proceso que oculta la pedagogía en su propuesta de la noción de formación, la contradicción entre formación y emancipación. La doctrinalidad es la cara oculta de la formación. El proceso formativo, tal como se ha planteado desde el siglo XVII y XVIII en las voces de Comenio y Herbart, es adoctrinante. Es por ello que el antídoto contra la formación integral es la decolonialidad holística de la mente humana.

La pedagogía coloniza, ya que su propuesta es la formación. Los profesores somos formadores que no formamos. Formar es dar forma, modelar. $Y$ nuestra misión como profesores -que profesamos- no es darle forma ni modelar al estudiante. Formar es colonizar. El currículo coloniza, porque su propuesta es la organización y estructuración de la vida escolar, organización de los contenidos, planear y estructurar el proceso de formación. Organizar, planear y estructurar es colonizar. La didáctica coloniza, porque su propuesta es la enseñanza, esa es su distinción y su totalidad, convirtiendo en exterioridad al aprendizaje. La didáctica incluye el enseñar y excluye el aprender, convierte en subalterno al estudiante. En la didáctica el profesor es un colonizador. Enseñar es colonizar.

La pedagogía coloniza y adoctrina cuando se preocupa por la formación. Porque se concentra en la estructuración del Otro. En el marco del currículo, cuando es el profesor quien planea, organiza y estructura, el proceso deviene en colonizante, porque priva al estudiante de la posibilidad de decidir. Cuando es el profesor quien opta por el estudiante sus decisiones curriculares colonizan. $\mathrm{Y}$ es eso precisamente lo que propone la teoría curricular moderna: organizar, planear y estructurar.

Ahora bien, Levinas (2014) nos hizo desviarnos de los caminos ontológicos que trazó el movimiento fenomenológico, por cuanto nos propone apartarnos de la epistemología que privilegia la relación sujeto-objeto. Debemos configurar una pedagogía que se concentra en la relación sujeto-sujeto, es decir, entre un yo con otro yo. El pensamiento de Levinas (2014) nos invita a apartarnos de la episteme europea moderna. A partir de su trabajo, su pensamiento, su acercamiento y método, su forma de interpretación y el camino de reflexión que abrió para sí, es necesario crear formas "otras" de enseñar, lo cual requiere la configuración de nuevos tipos de procesos formativos y nuevas ciencias de la educación cuya estructura categorial se sustente en el saber del Otro, considerado inferior, y no sólo en la pedagogía moderna/colonial, considerada superior. Entonces, no se trata solo de reconfigurar y reestructurar las ciencias de la educación en América Latina, urge decolonizarlas.

El giro decolonial de las ciencias de la educación es de 360 grados, pero no se regresa al mismo punto desde donde se gira, sino a un punto paralelo, y se continúa avanzando desde una mirada configurativa, sistémica, compleja y holística, con reconocimiento de los demás enfoques y paradigmas existentes, pero argumentando, asumiendo y sobre todo defendiendo que también existen formas "otras» igualmente válidas, útiles y pertinentes en/ desde/por/para el contexto donde se originan. Precisamente, en este artículo sugerimos cómo decolonizar las ciencias de la educación a través de lo que hemos denominado Altersofía (Ortiz y 
Arias, 2019) y Hacer Educativo Decolonial (Ortiz y Arias, 2018). Analizamos el por qué y para qué una didáctica "otra", así como la necesidad de transitar hacia un proceso formativo decolonizante. Finalmente, caracterizamos el hacer educativo decolonial como proceso formativo decolonizante, desarrollado mediante las acciones y huellas del contemplar comunal, el conversar alterativo y el reflexionar configurativo, las cuales caracterizan la vocación educativa decolonial.

Por otro lado, no son pocos los trabajos realizados en los que se propone decolonizar las ciencias de la educación. Estas deben desprenderse de su enfoque moderno/colonial, deben romper con su propio pasado y señalar nuevas rutas. Ahora bien, urge abandonar la noción de pedagogía, así como abandonamos las nociones de epistemología, metodología, didáctica, estrategia, método, técnicas, entrevista. Urge desengancharnos de las nociones de pedagogía y currículo. Urge desprendernos de la didáctica. No tenemos otra alternativa. De lo contrario, seguiremos encapsulados en la modernidad/ colonialidad eurocentrada y occidentalizada. Emerge así la Altersofía, no como un nuevo paradigma educativo o modelo pedagógico, sino como una opción, como una forma "otra" de educar, enseñar y evaluar.

\section{ALTERSOFÍA: DESPRENDIMIENTO DE LA PEDAGOGÍA MODERNA/COLONIAL}

Urge/emerge la crítica al paradigma educativo europeo modernidad/racionalidad. Este paradigma hace suyo el concepto de racionalidad, se apropia de éste, y descalifica a todos quienes no razonan así. Cualquier conocimiento que se oponga a la episteme eurocéntrica es considerado no válido, irrelevante, inferior, sesgado, parcial y poco serio. Ahora bien, no se trata de negar o rechazar esas categorías, sino de no seguirles el juego, desprendernos de ellas, no hablar en sus términos, desengancharnos de esa episteme pedagógica que nos aprisiona $y$, configurar discursos no solo cambiando el contenido de los términos pedagógicos, sino además las propias nociones que configuran las teorías educativas: pedagogía, currículo y didáctica.

Es cierto que urge decolonizar e indisciplinar las ciencias de la educación, configurar un "modelo pedagógico" fronterizo, desde los bordes, un "modelo pedagógico" decolonial, pero en realidad no se trata de proponer un nuevo "modelo" sino de asumir una opción diferente a la pedagogía occidental. En este sentido, Mignolo (2013) considera que es necesario el desenganche. Sin embargo, ¿se necesita una pedagogía decolonial o lo que necesitamos es configurar saberes "otros" y formas "otras" de educar, enseñar y evaluar?, ¿necesitamos configurar otra pedagogía que enfrente a la pedagogía moderna/colonial o necesitamos configurar una altersofía como opción para desprendernos de - y desobedecer a - la pedagogía y la didáctica occidentalizadas?

Necesitamos un pensamiento alterativo, no alternativo, sino alterativo, que incluya, reconozca, valore y visibilice al otro, desde un nosotros emancipado que practica la autodecolonialidad. El pensamiento alterativo se configura con/desde/por/para el otro, pero no para conformar binas, sino en el marco de la comunalidad, que es su atributo esencial. El pensamiento alterativo es ontológicamente comunal, teleológicamente decolonial y epistemológicamente situado.

El saber es la base y cimiento del hacer. La pedagogía es el sustrato y la base de la didáctica moderna/colonial. Asimismo, la sabiduría y la forma de conocer del otro (altersofía) es el sustrato y la base del hacer educativo decolonial. De ahí que, la altersofia (no la pedagogía) es la base y el cimiento del hacer educativo decolonial, por cuanto todo proceso formativo decolonizante implica al otro y su saber, su conocimiento situado, su forma propia de aprender. Emerge así la altersofía (sustrato 
del Hacer Educativo Decolonial): configuración "otra" para el contemplar comunal, el conversar alterativo y el reflexionar configurativo, como acciones/huellas decoloniales que median el tránsito desde la decolonialidad hacia la comunalidad, pasando por la alteridad. Una configuración de configuraciones que estimula y potencia un pensamiento alterativo como cimiento de los convivires comunales.

El ser humano es inmanente a la macroconfiguración cosmológica. Entonces, siendo así, ¿quién piensa?, ¿quién aprende?, ¿quiénconoce?, ¿quiénconfiguraconocimiento?, ¿por qué, para qué y para quién lo hace? Estos interrogantes nos llevan a cuestionar y problematizar la pedagogía y configurar la altersofía. Ahora bien, ¿esto significa que estamos comenzando desde el final?, ¿significa esto que forzamos el fin? No debemos entender la configuración conceptual comprensiva como un fin, sino como un medio para alcanzar el fin, un puente, un viaducto. Porque observamos, conversamos, reflexionamos y vivimos desde esas configuraciones conceptuales comprensivas. Debemos atrevernos a llamar las cosas desde lo que se va viviendo en cuanto a lo decolonial. En realidad, no existe final, cada día emergen nuevos pensares y sentires. $Y$ cuando cambiamos los términos, y no solo el contenido de éstos, entonces iniciamos el decolonizar, el desprendimiento, el desenganche, el reconfigurar, el re-vivir, la desobediencia. En realidad, no hay inicio ni final, es un continuo dinámico, configurativo, oscilántico, como el vuelo de las mariposas. El desmarque emerge desde el vivir. Es en/ desde/por/para el vivir decolonial que aflora la configuración conceptual.

Nos decolonizamos a partir de que vemos que colonizamos en nuestra práctica pedagógica y así mismo nos colonizan desde sistemas y estructuras educativas "superiores". EI decolonizar lo iniciamos desde que escogimos la decolonialidad como una opción para formar, una vocación, una actitud, un estilo, una forma "otra" de educar, enseñar y evaluar. Desde que sentimos esa necesidad emprendemos el camino de soltarnos de las ataduras pedagógicas coloniales. $Y$ en el educar decolonial nos damos cuenta de que estamos atrapados en el lenguaje moderno, que también es colonial, excluyente, depredador y patriarcal. En ese sentir emerge aquello que en nuestro interior hemos sentido sin darle un nombre tal vez, pero llega el momento que se da y se concibe. Debemos darle valor al lenguaje de las culturas en las cuales nos encontramos y develarlo a la comunidad académica a través del hacer educativo decolonial.

Parece que el término es el inicio, pero no es así. El término es el final temporal de un proceso, pero a la vez es el inicio temporal de otro proceso. El término es una contingencia vital. Nos da vida y también nos la quita. El sustrato es el vivir, el hacer/actuar/vivir es lo único que tenemos. El lenguaje no es un sistema de signos, el lenguaje es nuestro modo único de vivir en comunalidad. Hay cosas que nunca decimos, que nunca soltamos, pero que hacen parte del convivir y cuando nos atrevemos a hacerlo nos damos cuenta del valor de la alteridad porque allí verdaderamente nos reconocemos. Definitivamente, somos en el otro, pensamos en/desde/por/para el otro, vivimos por/para/en/ desde el otro. No somos sin el otro. No existe en el planeta tierra el ser humano, existimos en el planeta tierra los seres humanos, el vivir humano no es singular sino plural. Como solía decir Arendt (2014): la pluralidad es la ley de la tierra.

El conocimiento se configura de manera local y situada, "la 'historia' del conocimiento está marcada geo-históricamente y además tiene un valor y un 'lugar de origen'. El conocimiento no es abstracto y deslocalizado (Walsh, 2002), lo 
cual no significa que está desconectado de las dinámicas socioculturales.

No es posible decolonizar sin una altersofía armónica y coherente, que responda a las formas otras de aprender y educar-se del subalterno. No se trata de configurar otra pedagogía, ésta es una noción eurocéntrica $\mathrm{y}$, por tanto, moderna/colonial. Pedagogía se refiere al cuidado/formación del niño, una visión "válida y verdadera", en cambio sofía se refiere a una forma particular de aprender y a un conocimiento personalizado, situado, no necesariamente verdadero universalmente, pero sí verdadero y válido para el subalterno sentipensante. La altersofía garantiza, reproduce y conserva el vivir del sujeto subalterno y es la base y cimiento teórico y praxiológico del hacer educativo decolonial como proceso formativo decolonizante. Ambos, la altersofía y el hacer educativo decolonial, mediante sus tres acciones constitutivas (contemplar comunal, conversar alterativo y reflexionar configurativo) constituyen una diada o bina sófica (no pedagógica) potenciadora del pensamiento alterativo en función de configurar convivires comunales. De esta manera, continuamos avanzando junto a Mignolo (2013), no solo cambiando el contenido de los términos, sino los propios términos, e incluso rescatar algunos términos originarios (Grosfoguel, 2007).

En el vivir subyace el pensar/conocer. El lenguaje es inmanente al vivir. Vivimos en el lenguaje. En el vivir configuramos cultura mediante el lenguaje. Por eso para decolonizar el vivir hay que decolonizar el lenguaje, el conocimiento y el pensamiento. La colonialidad del poder, del saber y del ser, están transversalizadas por la colonialidad del lenguaje. No fueran posibles aquellas sin ésta. La colonialidad lingüística es una configuración tríadica que entrelaza la colonialidad del poder, del saber y del ser, mediante la violencia ideopolítica y epistémica. De ahí que, debemos desprendernos de las configuraciones conceptuales que nos colonizan, sobre todo la retórica de la modernidad, en la cual subyace la lógica de la colonialidad. De ahí la urgencia/emergencia de una gramática propia de la decolonialidad. Los términos están emergiendo en/desde/por/para nuestro vivir comunal. Emergen desde nuestro hacer educativo decolonial.

Por otro lado, es preciso entender la raíz civilizacional del problema y la cuestión colonial (que es esencialmente teológico y racial), y tampoco podemos negar totalmente el saber occidental -pero sí desprendernos de algunas categorías coloniales- pues la colonialidad no solo subyace las teorías eurocentradas sino nuestra forma de pensar y de configurar la realidad. Todas las lenguas indoeuropeas son occidentalocéntricas, obedecen a los cuatro paradigmas con que Occidente configura la realidad, por ejemplo, en las lenguas indígenas no existe el verbo Ser, no están separados de la realidad, del cosmos. Precisamente una de las primeras acciones de Europa desde 1492 fue imponernos las lenguas coloniales: español, portugués, inglés. Por eso es esencial desprendernos de las nociones coloniales como pedagogía, currículo y didáctica. Sabemos que no es tan fácil, pero debemos desmarcarnos de la retórica de la modernidad. Estas acciones/huellas decoloniales forman parte del desprendimiento y desenganche de la pedagogía occidental/eurocéntrica/colonial, para no seguirle el juego nocivo a la retórica de la modernidad, sino apartarnos de la lógica de la colonialidad, proponiendo una gramática propia de la decolonialidad. Es decir, se trata de sentir/ pensar/hacer con nuestras propias nociones y no importar categorías eurocentradas. Debemos ir más allá de la pedagogía. Sabemos que no podemos desprendernos del todo: por eso nunca habrá descolonialidad, pero sí decolonialidad.

Ir más allá de la pedagogía implica deconstruirla (Derrida, 1998), reconfigurarla (Ortiz, 2013), e 
incluso destruirla (Heidegger, 2012). Esto es posible mediante la altersofía: la sabiduría del otro, del subalterno, su senti-pensar, su forma de aprender y educar-se, su conocimiento situado y contextualizado, que ha sido invisibilizado por la pedagogía occidental/moderna/eurocentrada, que es colonial/excluyente//depredadora.

No es posible negar u ocultar el epistemicidio, debemos entender que el concepto de pedagogía es en sí mismo epistemicida. Hay autores que usan pedagogía en el mismo sentido que se usa altersofia, lo cual es un error conceptual, ya que la pedagogía y la didáctica se sostienen en la negación del conocimiento del otro, al considerarlo objeto, al asumirlo como "inferior" y pretender erigirse como único conocimiento válido, superior y universal, lo cual es una falacia.

Es decir, la pedagogía y la didáctica, tal como la conocemos, han sido -y son- depredadoras de las sofías subalternas, tan válidas como aquellas, que se erigen universales y se autonombran verdaderas y únicas, globales. La única forma de trascender la pedagogía e ir más allá de ella (configurar una metapedagogía) es desenmascararla, y rescatar/ visibilizar/valorar las sabidurías subalternas, colonizadas, invisibilizadas, es decir, amplificar y alzar la voz del "otro" (subalterno, colonizado). Solo lograremos desprendernos y decolonizar las ciencias de la educación cuando el alter subalterno hable en todas las tribunas, $y$ la academia se humille $y$, con humildad, reconozca, valore y asuma las sofías de ese alter colonizado, o sea, cuando la pedagogía moderna/colonial reconozca y respete la sofía subalterna, y cuando la Altersofía coexista con la pedagogía occidental/eurocentrada. En este sentido, ¿cómo se definiría altersofiar? Amar al otro y permitir/promover que el otro te ame. Es la acción comunal del amor, para lograr el educar, el enseñar y el evaluar, porque no hay conocimiento sin amor. Esto es la altersofía, una forma de educar que brinda oportunidades de emancipación y reconocimiento a los subalternizados, interpelando con los paradigmas establecidos dominantes, proponiendo diálogos sóficos pluriversales, sin intentar imponerse de forma dogmática, sin adoctrinamientos, ni dominación.

El argumento central de la Altersofía está filosóficamente formulado en los planteamientos de Las Casas (1942). Es decir, la altersofía exige tener en cuenta la libre voluntad del oyente para que sin coacción pueda aceptar las razones racionalmente y exponer las suyas propias. La altersofía implica contemplar al otro de manera amorosa, es decir, permitir y promover una percepción "alocéntrica", tal como lo propone Fox-Keller (2000), para recuperar la génesis emocional de la actividad educativa: la pulsión amorosa. Esta posición también ha sido defendida por Maturana (2003), quien define el amor como la emoción que funda lo humano, representada en la acción de aceptar al otro en la convivencia. Amar y aceptar al otro implica aprender a escuchar. Ahora bien, es preciso tener en cuenta que mientras más universal se pretenda un saber, menos válido y verdadero es. Mientras más local es un saber, más verdadero es. El saber es más verdadero mientras más situado está y más se relaciona con las biopraxis humanas individuales y particulares.

Una condición necesaria para el despliegue de la altersofía es que haya igualdad entre poderes, saberes e interlocutores. La altersofía es una configuración neutral en donde se entrelazan la inmensa variedad de sofías (saberes "otros") existentes en un territorio determinado, donde lo esencial no es la "cosa en sí" sino el sentirpensar de quien habla. La altersofía no privilegia el discurso ontológico que reifica el saber, sino que exalta la interioridad del hablante y no el ser de las cosas. Desde esta mirada, no es necesaria una "pedagogía del sur" que encauce "...la búsqueda de conocimientos y de criterios de 
validez del conocimiento que otorguen visibilidad y credibilidad a las prácticas cognitivas de las clases, de los pueblos y de los grupos sociales que han sido históricamente victimizados, explotados y oprimidos, por el colonialismo y el capitalismo globales" (Santos, 2009, p. 48). Estos conocimientos y formas de educar-se y aprender se autorrepresentan y autoconfiguran, no es necesario buscar criterios para validarlos y darles credibilidad, lo que debemos hacer es darles la palabra, reconocerlas desde su propia voz, ya que son válidos y creíbles para los pueblos mismos y han sido el fundamento de su vivir, aunque no sean reconocidos por la pedagogía y la didáctica USA-eurocéntricas.

\section{HACIA UNA DIDÁCTICA “OTRA”}

Cuando hablamos de didáctica, es necesario tener en cuenta desde qué posición estamos hablando, ya que podemos hablar desde el profesor o desde el estudiante. No es un secreto que la noción de 'didáctica' es eurocéntrica, es un concepto griego cuyo significado es Yo Enseño, pero está muy ligado a la conquista europea, nos llegó desde la invasión y saqueo de las tierras de Abya Yala en 1492. De ahí que el término didáctica está ligado de manera indisociable al imperialismo y al colonialismo de Europa, y prolifera en nuestros días mediante la colonialidad pedagógica y curricular.

No es lo mismo hablar de didáctica desde la óptica del profesor y colonizador, que hablar de didáctica desde la mirada del estudiante y colonizado. Toda didáctica es colonizante. Todo profesor es colonizador. Desde la perspectiva del estudiante, la palabra didáctica es probablemente una de las palabras más colonizadoras en el vocabulario pedagógico. La didáctica fue asumida en/desde Abya Yala como un proceso deshumanizante, un conjunto de acciones de enseñanza colonizantes que han causado dolor y sufrimiento a los estudiantes.
El imperialismo, el capitalismo y el colonialismo, constituyen la tríada que han configurado la didáctica como mecanismo de dominio, regulación y control, mediante la creación de nociones autoritarias que devienen en argumentos para manipular, doblegar y obligar, como son los conceptos de correcto/incorrecto, objetividad, verdad y realidad externa. Algunos académicos, pedagogos e intelectuales de Occidente, personalidades eurocentradas, así como las universidades e instituciones educativas, patrocinadas por el Estado, regulan, controlan y colonizan mediante el establecimiento de reglas formales y normas universales para gestionar la educación y la academia, mediante modelos pedagógicos impuestos y a través de estrategias pedagógicas rígidas y dogmáticas, cuyo resultado es la colonialidad pedagógica y curricular.

Son estas mismas configuraciones de colonialidad las que regulan la perspectiva convencional de la educación como un modo de subalternizar culturas. Se necesita una forma de educar que brinde oportunidades de emancipación a los subalternizados, interpelando con los modelos educativos establecidos dominantes, proponiendo diálogos pedagógicos pluriversales, sin intentar imponerse de forma dogmática, sin adoctrinamientos, ni dominación. Se trata de identificar que nuestras formas de educar proceden de un proceso colonizante permeado por la incapacidad de formar, enseñar y evaluar conforme a nuestras necesidades, intereses y preferencias.

Los modelos pedagógicos, los programas académicos universitarios y los medios de comunicación contribuyen a establecer configuraciones sígnicas educativas que proliferan y se instauran en la práctica pedagógica, configurando así la colonialidad de la pedagogía, el currículo y la didáctica. De ahí que, se requiere desplegar un proceso formativo 
decolonizante ${ }^{4}$ de la didáctica, transitar hacia una no-didáctica y configurar nuevas formas de educar, enseñar y evaluar, reinventar la pedagogía, y proponer nuevas prácticas pedagógicas y curriculares que no colonicen al estudiante, que no conviertan al profesor en un colonizador.

Hoy es un imperativo reflexionar sobre cómo formamos, cómo educamos, enseñamos y evaluamos; problematizar y cuestionar nuestras propias prácticas curriculares, nuestras creencias pedagógicas, y reconocer con humildad que nuestras concepciones pedagógicas, curiculares y didácticas no constituyen un sistema de reglas, no son una configuración normativa, no representan un saber universal, no constituyen una verdad absoluta.

La altersofía y el hacer educativo decolonial tratan de subsistir en una época de incertidumbre global. Son el David que lucha incesantemente contra el gigante Goliat (las ciencias de la educación establecidas). En la actualidad proliferan nuevos estándares y normas "universales" para el diseño y desarrollo curricular, así como la confiabilidad y validez del proceso formativo.

A partir de lo anterior, muchos académicos, educadores e intelectuales comprometidos con los subalternos y colonizados estamos configurando vínculos profesionales encaminados a deconstruir, reconfigurar y decolonizar las formas tradicionales de educar, enseñar y evaluar. Hoy estamos aprendiendo a desmontar, desmantelar y desconfigurar las ciencias de la educación establecidas e impuestas, estamos develando la máscara del paradigma educativo dominante y vigente. Ya hemos aprendido que la didáctica siempre es ética, moral, político e ideológica, comprometida socialmente.

En la década de los años 60 , asistimos a una amplia y profunda discusión epistemológica

\footnotetext{
4 Un proceso decolonizante es aquel que propicia la comprensión crítica, reflexiva, creativa y configuracional de las intenciones, valores, motivaciones, postulados y supuestos educativos que subyacen y configuran las prácticas formativas.
}

sobre el estatuto científico de la pedagogía y la didáctica. Las mal llamadas ciencias duras cuestionaron con fuerza el carácter científico de la pedagogía. Las teorías pedagógicas fueron relegadas a un segundo plano, no científico, entendiendo que no garantizaban la objetividad del proceso formativo. Sin embargo, la pedagogía y la didáctica se sentían orgullosas de sus bondades: humanismo, comprensión, transformación. La pedagogía crítica enarbolaba las banderas de la interpretación, la subjetividad y la liberación.

Mientras la pedagogía y la didáctica luchaban por encontrar una posición en la cúspide científica, los estudiantes seguían siendo sometidos a los autoritarismos de ambas perspectivas formativas. De esta manera, ambas, tanto la pedagogía como la didáctica, se convertían en tendencias y corrientes educativas colonizadoras, promoviendo el desarrollo de un proceso formativo colonizante. Así emergió la coIonialidad pedagógica, curricular y didáctica. En efecto, tanto la pedagogía como la didáctica son dos teorías/procesos colonizantes. El reto es deconstuirlas, para romper con la dicotomía pensamientolcuerpo e imprimir de pluriversidad a las diversas formas de educar, enseñar y evaluar. Es lamentable que la pedagogía y la didáctica pretendan asumir la denominación de científica, convirtiéndose en teorías que buscan el poder y la verdad, convirtiéndose así en teorías y prácticas colonizadoras, que generan un conocimiento colonial, subalternizando otros saberes y seres. Estas tendencias deben ser deconstruidas y descolonizadas desde un horizonte mundial pos-occidental, anti-capitalista y anti-patriarcal. Aunque declaran una actuación desde lo emic, dándole la voz a los estudiantes, en realidad el profesor tiene la última palabra, actúa desde lo etic, oculta la voz de los otros bajo la fuerza de su propia voz, lo emic queda sepultado en lo etic, se produce un traslapa- 
miento de las voces de los estudiantes por la voz del profesor, lo emic queda solapado en lo etic.

No solo la pedagogía y la didáctica tradicionales, generadas desde un enfoque psicológico conductista, son colonizadoras. La pedagogía crítica también es colonizante. Al pretenderse científica, imita determinados rasgos y características de la ciencia educativa moderna/colonial, y se cree con el derecho de proporcionar el cimiento de las configuraciones psicosociales del sujeto que aprende, es decir, del estudiante. El "otro" es colonizado, queda representado por el profesor, quien se convierte en un colonizador, cercenando así las más nobles aspiraciones del estudiante de aprender y educarse en una escuela más justa y equitativa. Es preciso eliminar la tara colonial que enmarca los vestigios concomitantes de la mirada educativa y pedagógica; fundada en los límites de nuestra visión que debería ser holística, sistémica, compleja y configuracional.

La utopía de configurar una escuela libre y democrática exige a las ciencias de la educación y a los procesos formativos que se interesen, preocupen y ocupen de los anhelos, aspiraciones, esperanzas, metas, necesidades y sueños de los estudiantes. ¿Qué sentido tendrían la pedagogía y la didáctica si no están encaminadas a configurar la felicidad, la paz, la armonía, la seguridad y el vivir pleno de todos y cada uno de los estudiantes? Esta intención no es lograble utilizando los modelos pedagógicos que han proliferado a lo largo de la historia de la educación ni las estrategias pedagógicas que aparecen en la literatura publicada. Se necesita una didáctica "otra" que propicie un proceso formativo decolonizante.

Definimos la «didáctica otra» como la heterogeneidad en las maneras de formar, enseñar y evaluar en la realidad educativa colonial. Hablamos de una "didáctica otra"; no de una didáctica nueva, ni de un modelo pedagógico emergente, que supere a los modelos pedagógicos anteriores. Nos referimos a una didáctica que facilite una narrativa en clave decolonial, que tenga en cuenta las historias coloniales solapadas, la diferencia colonial y las historias locales, cuyo potencial educativo-formativo ha sido ocultado, negado o ignorado.

Con la noción de "didáctica otra" buscamos configurar una mirada no lineal de los modelos pedagógicos y estrategias de enseñanza; buscamos eliminar la idea moderna/colonial de que los paradigmas educativos y modelos pedagógicos se suceden uno a los otros, superando y reemplazando a los anteriores. La "didáctica otra" reconoce la diferencia colonial que caracteriza la ontología de la educación, es decir reconoce la diversidad como proceso emancipatorio de los estudiantes, que permita la decolonialidad de las identidades fraccionadas.

Desde esta perspectiva, una didáctica "otra" no se refiere a un conjunto de estrategias de enseñanza o a un nuevo modelo pedagógico o método universal para enseñar, que pretende ser la panacea o el camino verdadero que supera a todas las formas de educar, enseñar y evaluar, previamente existentes. La didáctica "otra" es otra opción, tan válida como las existentes. Es una opción educativa decolonial, que configura una nueva narrativa, un nuevo discurso, una nueva forma de pensar y de educar, enseñar y evaluar, que se diferencia de -y es incompatible con- los modelos educativos y estrategias pedagógicas configuradas por los enfoques y paradigmas modernos.

La pedagogía crítica no es ajena a la didáctica decolonizante, pero no constituye un referente para la validez, confiabilidad y legitimidad educativa. El proceso formativo decolonizante es una necesidad de reconocimiento, de visibilización, de autovaloración a nivel educativo, ético y político, sobre todo para las ciencias de la educación de Abya Yala. Esto ha sido refren- 
dado por Mignolo (2013) al invitarnos a cambiar no sólo los contenidos de los términos, sino también los propios términos y las condiciones de nuestro discurso. Asimismo, Escobar (2003) puntualiza que no debemos contribuir a los sistemas de pensamiento eurocéntrico ya establecidos, sin importar cuán críticos sean éstos, sino que nuestro propósito debe ser labrar nuevas formas de análisis.

Por otro lado, Semali y Kincheloe (1999), y Mutua y Swadener (2004) alertan que es necesario decolonizar y deconstruir las estructuras epistemológicas y metodológicas dentro de la academia occidental eurocentrada, ya que los sistemas de conocimiento occidental y sus epistemologías se han generalizado y son considerados como universales, sin serlo.

Mientras más universal se pretenda un saber, menos válido y verdadero es. Mientras más local es un saber, más verdadero es. El saber es más verdadero mientras más situado está y más se relaciona con las biopraxis humanas ${ }^{5}$ individuales y particulares. Solo podrá actuar con espíritu decolonizante el profesor que se identifique con el grupo estudiantil. Si el profesor no ama a sus estudiantes es muy difícil que pueda desplegar una práctica educativa decolonizante, porque no está imbuido de su realidad, de sus reflexiones, de sus relaciones, accionares, sentires, sueños, deseos, tradiciones, costumbres y valores. Es decir, no constituye una voz de/en/para la comunidad estudiantil. Para lograrlo tendría que ejecutar acciones que no le permitan convertirse en un colonizador, es decir, tendría que desarrollar un proceso formativo decolonizante.

¿Esto nos conduce a un relativismo posmoderno? Si toda verdad esta situada, es local y contextual, ¿entonces todo es contextual y todo

5 Las biopraxis humanas representan las actividades, acciones y operaciones más concretas y especificas que desarrolla una persona en su cotidianidad, en su vivir espontáneo cotidiano. Las biopraxis están conformadas por los fragmentos del vivir humano, los momentos e instantes que configuran su vida diaria. vale? La pretensión de universalidad conceptual, pedagógica y didáctica es menos válida y menos verdadera. No obstante, la universalidad se podría conseguir bajo el intento de articular los saberes locales bajo un criterio que podría ser las biopraxis. En efecto, las biopraxis es un criterio universal que articula las verdades situadas, locales y contextuales.

No son pocos los intentos que se han realizado para configurar propuestas didácticas decolonizantes. No obstante, estos valiosos intentos se estancan en el diseño de modelos didácticos para apicarlos a las prácticas pedagógicas y la formulación de alternativas curriculares, que constituyen derroteros posibles hacia la decolonialidad de la educación, pero no hacen propuestas educativas concretas, configuradas solamente desde y para lo decolonial, sino que aplican criterios pedagógicos convencionales y tradicionales, criterios paralelos o cuasi-fundacionales, pero no aplican criterios propios de autenticidad decolonial ni criterios emergentes para un mundo transmoderno.

Entemos por mundo a las configuraciones lingüisticas en las que vivimos los seres humanos. Es preciso recordar que somos seres lenguajeantes, configuramos la realidad en que vivimos a través del lenguaje. Somos configuraciones lingüisticas. El lenguaje no es solo un sistema de signos, es el modo en el que vivimos los seres humanos. No existe nada fuera del discurso. No existe nada fuera del relato. No existe nada fuera de la narrativa. No existe nada fuera del texto. Por eso existen nociones coloniales y nociones decoloniales. Por eso debemos decolonizar el lenguaje y la mente humana. El primer paso para decolonizar las ciencias de la educación es reconfigurar y renombrar el mundo lingüistico en el que vivimos los actores educativos, desprendiéndonos de las nociones educativas coloniales y configurando nociones educativas decoloniales. 
Innumerables modelos pedagógicos ofrecen la posibilidad de que los estudiantes presenten aportes desde su perspectiva, pero no tienen una mirada holística para configurar un proceso formativo decolonizante, mediante un conversar, un contemplar y un reflexionar decoloniales, que sea verdaderamente un proceso indisciplinado, de frontera; una no-didáctica. Casi todos los modelos pedagógicos se configuran desde una mirada teleológica, y no emergen las acciones didácticas decoloniales.

Las teorías del aprendizaje constructivista y los modelos educativos de la pedagogía crítica y de la escuela activa y participativa están muy cerca de lo que estamos pensando cuando reflexionamos sobre la urgencia de decolonizar las ciencias de la educación. Se acercan, pero no llegan a dónde nosotros pretendemos y necesitamos llegar: la decolonialidad pedagógica, curricular y didáctica. Es preciso dar un paso más: develar la esencia de un proceso formativo decolonizante, sus criterios/principios/acciones/huellas. Su propuesta, aunque extraordinariamente valiosa, no es suficiente, porque es conservadora, por mantener intactos los conceptos de la tradición conductista y colonizadora. Parafraseando a Mignolo (2013), cambian el contenido de los términos, pero quedan atrapados en las redes conceptuales de las nociones convencionales eurocentradas. No dan el paso final de modificar no sólo el contenido de los términos sino modificar también los propios términos. Entonces, al proponer una pedagogía crítica y una didáctica activa y participativa, éstas siguen siendo una pedagogía y una didáctica, aunque se configuren desde la idea de la emancipación y la democracia.

Toda pedagogía y toda didáctica, por su propia esencia ontológica, son colonizantes. De ahí que, para decolonizar las ciencias de la educación, sea necesario situar la pedagogía y la didáctica en un contexto cultural más amplio y hacer la autocrítica desde dentro del mismo pro- ceso formativo, reconociendo a cada estudiante como el otro-yo, dialogando afectivamente entre iguales y reflexionando desde una perspectiva holística e integradora. El proceso formativo decolonizante debe ser ético, respetuoso, sociable, solidario y útil. Decolonizar las ciencias de la educación implica no sólo formar desde la altersofía y enseñar desde didácticas "otras", sino también cuestionar el contenido de dicha noción y cuestionar incluso el propio término. Implica develar otras formas de enseñar y evaluar sin subalternizar, sin dominar las acciones humanas ni los ideales de los estudiantes. Implica formar en/por/para la propia comunidad estudiantil que pretende decolonizarse. De ahí que todo proceso formativo decolonizante sea una autodecolonización.

El proceso formativo decolonizante debe ser guiado por principios democráticos. Debe estar implicado dialógicamente con la comunidad estudiantil, respetar la autonomía cultural y el derecho a la autodeterminación. Debe ser honesto y orientarse a cumplir propósitos de equidad, dignidad y justicia social. Debe estar encaminado a satisfacer las necesidades de los estudiantes. No debe limitarse solamente a un paradigma educativo, enfoque pedagógico, modelo curricular o estrategia didáctica. Debe ser armónico y coherente, pero puede combinar modalidades de formación, enseñanza y evaluación. Debe ser creativo, crítico, reflexivo, disruptivo y configuracional.

El proceso formativo decolonizante no es neutro. Todo proceso formativo decolonizante es político e ideológico. El actor/mediador decolonial debe actuar de tal manera que su hacer educativo beneficie a la comunidad participante y promueva la autonomía de todos y cada uno de los estudiantes, teniendo en cuenta discursos colectivos, entendiendo las diferentes dimensiones de un mismo fenómeno y las dificultades para coincidir en sus puntos de vista. La didáctica desde la perspectiva 
de la decolonialidad debe convertirse en una configuración de dialogares, un espacio para el conversar alterativo, un conversar entre iguales, libre y espontáneo, sin a prioris, sin supuestos, sin condiciones ni expectativas, sin exigencias. El proceso formativo decolonizante debe conversar de manera crítica y reflexiva sobre las clases, comunidad, democracia, equidad, estado-nación, género, globalización, justicia social, libertad y raza, entre otras configuraciones heurísticas que hoy dinamizan el sentir-pensar humano.

Es importante que el proyecto educativo decolonizador incluya dentro de sus objetos de estudio a los paradigmas y enfoques de la pedagogía clásica moderna/capitalista/colonial y haga una contundente crítica a los sistemas educativos occidentales y eurocéntricos. La pedagogía decolonial implica investigar a la didáctica sustentada en el paradigma clásico dominante. EI hacer educativo decolonial exige dejar ir. Debemos desengancharnos de -y dejar ir- los postulados de los enfoques y modelos pedagógicos universales, y de las estrategias tradicionales de la didáctica, asumiendo posturas políticas y no sólo pedagógicas. En el proceso formativo decolonizante lo político está al servicio de lo pedagógico y viceversa. Lo político y lo pedagógico son dos caras de la misma moneda. Configuramos la pedagogía desde posiciones ideopolíticas decoloniales, y configuramos la ideología asumiendo opciones pedagógicas decoloniales.

Denzin (2003) afirma que lo performativo es siempre pedagógico y lo pedagógico es siempre político. En este sentido, el proceso formativo decolonizante debe ser situado y localizado, debe sustentarse en los sentidos y significados específicos que atribuyen los estudiantes a sus prácticas, costumbres, tradiciones, estilos, estrategias y hábitos de aprendizaje. En el proceso formativo decolonizante, los problemas, intenciones y métodos no deben generalizarse, deben asumirse como características que de- penden de la historia, contexto y agencia.

El proceso formativo decolonizante debe basarse en prácticas performativas en las que prolifere el amar, el respetar, el sensibilizarse, el cuidar, el acompañar, el compartir y el solidarizarse. Este proceso asume una visión holística, configurativa, dialéctica y sistémica del aprendizaje. Concibe al estudiante como un agente activo y no como un receptor pasivo, por eso cuestiona las estrategias pedagógicas tradicionales, porque son colonizadoras. En este proceso no hay un profesor que enseña a los estudiantes, no hay un profesor que transmite conocimientos, más bien hay un mediador que incita al conversar alterativo, un facilitador que promueve el contemplar comunal, el co-contemplar, donde todos nos contemplamos desarrollando nuestras prácticas co-formativas. Como diría Freire (1994, 1997, 2009, 2011, 2012a, 2012b, 2013, 2014), nadie educa a nadie, nadie se educa solo, nos educamos entre todos.

Una de las acciones y huellas del proceso formativo decolonizante es el conversar alterativo. Lo único que garantiza un conversar alterativo es no intentar imponer una cosmovisión, o una razón universal. El argumentar decolonial no coloniza cuando se hace sin supuestos, sin aprioris, sin expectativas, solo a partir de la reflexión afectiva. Para ello ambas partes de la conversación deben reflexionar basados en la misma emoción. Si una de las partes fluye en la emoción del amar y otro fluye en la emoción del odio o resentimiento, entonces no habrá acuerdos ni configuración conceptual. El consenso sólo se logra cuando ambas partes fluyen en la misma emoción: el amar. Esbozar un argumento no es colonizar, cuando lo hacemos soltando nuestras creencias, dejándolas ir, y entendiendo que el otro también tiene razones. En consecuencia, el conversar alterativo es un reflexionar afectivo, basado en el amar, en el respeto, en la solidaridad, pero con honestidad, humildad, compromiso y responsabilidad. 
Para que emerja la configuración de la decolonialidad es preciso fluir en el amar, reflexionar y reconocer que el otro también tiene la razón. Ambas partes debemos fluir en la misma emoción del amar. En este sentido no hay decolonialidad global y holística sin vivir en el amar. Esto indica que debemos continuar configurando las ciencias educativas decoloniales, y transitar hacia una pedagogía "otra" que nos permita contribuir a estimular el pensar reflexivo de los actores y las competencias decoloniales requeridas para que desarrollen biopraxis cotidianas encaminadas a decolonizar su propia mente. El problema no es de forma sino de fondo, es sistémicoconfigurativo. La colonialidad del vivir corre por nuestras venas. $Y$ lo más triste es que a veces nos autocolonizamos, y con ello damos vía libre a la autocolonialidad del pensar, el hacer, el ser y el vivir.

Es muy complejo vislumbrar cómo serían estas nuevas ciencias de la educación en el futuro, es muy difícil caracterizar esos posibles horizontes, debido precisamente al carácter contingente e impredecible del comportamiento humano y social. No obstante, lo que sí es evidente es que las "ciencias" educativas decoloniales estarán más comprometidas con la vida, serán menos arrogantes y soberbias, más humildes, más responsables y comprometidas con el proceso de configuración del aprendizaje y el conocimiento, en el que el estudiante se asuma como centro, y la bondad amorosa se convierta en el tándem generador de conocimiento que contribuya a conservar, consolidar y reproducir la vida.

En ocasiones el educador disfruta la colonialidad en múltiples facetas del proceso formativo, nos encanta estar colonizados en muchos aspectos, teniendo la posibilidad de acceder a la decolonialidad nos autocolonizamos. Ese proceso de sentirnos y vivir subalternizados lo denominamos autocolonialidad. Nos hemos sumido en una sociedad que vive a expensas del pensamiento del otro, de no actuar por sí mis- mos, sino convertirnos en copia del otro que creemos original, no somos capaces de crear, proferir, tomar iniciativas, ser autodeterminantes para deshacernos del lastre de la momificación mental, del ser y del hacer.

Más allá de la colonialidad del poder, el saber y el ser hay otras dimensiones de la colonialidad, otras facetas o tipos de colonialidad, que incluso pueden contribuir a la colonialidad intelectual o cognitiva, a la colonialidad axiológica y política. Nos referimos a la colonialidad del vivir. No hay colonialidad del poder, del saber y del ser sin colonialidad del vivir. De ahí que, si queremos lograr la decolonialidad holística (poder, saber y ser) debemos en primera instancia acceder a la decolonialidad del vivir, y esto solo es posible mediante la decolonialidad de la cultura, para lo cual se requiere decolonizar el lenguaje, ya que nuestras configuraciones lingüísticas generan el mundo en que vivimos, nuestros discursos configuran nuestra cultura por medio del conversar. La decolonialidad holística solo es posible mediante la autodecolonialidad. $Y$ en este proceso autodecolonizante el reflexionar configurativo $y$ el conversar alterativo se convierten en acciones liberadoras y edificantes. En fin, reiteramos, el conversar alterativo es un conversar libre y espontáneo, sin supuestos ni expectativas, sin aprioris y sin exigencias, $\sin$ intentar imponer nuestra razón como única y universal, sin subalternizar al estudiante. Es un conversar incluyente, en el que todos tenemos la oportunidad y la posibilidad de decolonizar nuestro vivir por medio de la reflexión.

La única forma de ser decolonial es vivir sin supuestos, sin aprioris, sin expectativas, sin condiciones, sin exigencias. Lo decolonial no es una simple opción, es la única, es una necesidad, una urgencia. La única forma de vivir en plenitud es mediante la acción decolonial. Para todos nosotros los colonizados, estudiosos del proceso educativo colonizante, es la única opción para vivir en plenitud. Ahora bien, no es posible 
ser colonial/decolonial de manera simultánea. Una condición excluye la otra en las biopraxis humanas. Lo colonial excluye a lo decolonial, y viceversa. Cuando asumimos la decolonialidad no somos colonizantes. Por eso debemos practicar el conversar alterativo y el reflexionar configurativo en nuestro vivir y convivir cotidiano, para decolonizar de manera constante, aprovechando las grietas decoloniales de las que nos habla Walsh $(2013,2014)$.

Es cierto que existe una tensión dialectica entre lo colonial y lo decolonial, que es preciso trascender. ¿Podemos ser decoloniales absolutos sin ser colonizantes o coloniales? ¿Es posible borrar todo rastro colonizante desde una decoIonialidad radical? Imposible. El binomio colonial y decolonial es una necesaria contradicción constante en nuestra lucha bio-praxis. La decolonialidad existe precisamente porque vivimos en un mundo colonial. Si esta realidad colonial desaparece entonces dejaría de existir también la decolonialidad. Es por ello que utilizamos el prefijo De y no el Des, para denotar que lo colonial no se elimina totalmente, sino que es un proceso de desprendimiento y desobediencia caracterizado por la pluriversalidad, en la que emerge la decoIonialidad desde las grietas, solapando a la coIonialidad, produciéndose un traslapamiento de la colonialidad por la decolonialidad, hasta que aflora nuevamente la colonialidad en un estadio diferente de desarrollo y con rostros diferentes, los cuales garantizan que emerja nuevamente la decolonialidad. De esta manera, el binomio coIonial/decolonial no es una simple trampa o una falsa dicotomía a superar para pensar más allá de esas dicotomias que encarcelan las alternativas. El binomio colonial/decolonial es un atributo del mundo humano, psico-social y cultural.

La condición de colonizado se genera a partir de una acción colonizante del colonizador. No hay colonizado sin colonizador. No obstante, en ocasiones nos autocolonizamos. En este caso, utili- zamos la noción de autocolonialidad para aquellos seres humanos que sin vivir una relación con otro ser humano colonizador, se autocolonizan, es decir, se convierten en sus propios colonizadores. En esta variante o modalidad de colonialidad, el colonizado y el colonizador son la misma persona. A este proceso colonizante lo hemos denominado Autocolonialidad.

La autocolonialidad se manifiesta en múltiples dimensiones: pedagógica, curricular, didáctica, entre otras. Es posible, aunque no siempre sucede así, que la autocolonialidad tenga su génesis en un acto colonizante de un colonizador. Más bien pensamos que en múltiples operaciones de nuestro vivir cotidiano nos autocolonizamos. La autocolonialidad es una cualidad constitutiva del vivir del ser humano. De una u otra manera, de diversas formas, vivimos la autocolonialidad en diversos actos de nuestro vivir cotidiano. No obstante, es posible la autodecolonialidad. Más aún, es una de las posibles soluciones para la decolonialidad holística. No hay decolonialidad plena y global sin autodecolonialidad.

Maldonado-Torres (2006), en su idea de giro decolonial, ha escrito lo que él denomina "Bosquejo de diez tesis sobre colonialidad y decolonialidad". Si intentamos encasillar la noción de decolonialidad en tesis, la trivializamos, la convertimos en mercancía, y solo será útil para venderla. La decolonialidad no tiene tesis, ella misma es una tesis, no es un producto, tampoco un resultado, ni puede reducirse a un número. La decolonialidad no es una estrategia didáctica, es un proceso que permite identificar qué tan colonizados estamos y de qué elementos nos podemos apropiar/desenganchar para una reflexión permanente de nuestro hacer cotidiano.

La decolonialidad, en tanto proceso formativo, no debe tener guía orientadora. No hay nada más colonial que la orientación. La decolonialidad es libre, espontánea, y se despliega sin orientaciones, sin supuestos, sin aprioris, sin exigencias, sin expectativas. Orientar es colonizar. 
De ahí que, el proceso formativo decolonizante debe tener en cuenta el potencial del conversar alterativo y el reflexionar sin supuestos, sin aprioris y sin expectativas, solo desde el propio conversar liberador y el reflexionar edificante.

La decolonialidad radical, libre y espontánea es una forma de conduccción amorosa. Pero el amor no requiere de orientación, el amor es libre y espontáneo, emerge afectivamente desde las entrañas de los seres humanos que se aman. Por ejemplo, hablar de orientación amorosa de una madre o un maestro que ama a su hijo es una contradicción en sus propios términos, una auto-contradicción, ya que cuando se ama no se orienta. ¿Podemos educar sin orientar? Por supuesto que sí, porque la educación debería ser un proceso libre y espontáneo de interacción humana, conducente a la transformación.

La interación amorosa con los niños, no es conducción ni es orientación, en el sentido de conducir un automóvil u orientar a alguien que ejecute una determinada acción, sin tener en cuenta su voluntad. La interación amorosa con los niños es relación afectiva, libre y espontánea. Por ejemplo, un conversar amoroso, sin supuestos, sin aprioris, en una escuela primaria, implica que el maestro, de manera espontánea, se sitúe en una posición de humildad, al servicio de los niños, de sus necesidades, intereses, anhelos y expectativas, que subordine la enseñanza al aprendizaje, y que cada palabra que exprese esté en función de satisfacer las más auténticas y legítimas bio-praxis de los niños y niñas, sin el sesgo que implican los supuestos, los aprioris y las condiciones, que casi siempre se configuran desde la voluntad del maestro y no desde la configuración volitiva de los niños y niñas que, en última instancia, deben ser los beneficiarios de dicho proceso formativo.

Los colonizados configuramos la historia y las condiciones en nuestro vivir cotidiano, mediante el amar, el reflexionar configurativo y el conversar alterativo. De esta manera configuramos la autodecolonialidad, sin indicaciones ni orientaciones, porque si seguimos las orientaciones de las tesis entonces el orientador, escritor de tesis, se convierte en colonizador. Por eso la única tesis necesaria para educar es la propia decolonialidad de nuestro vivir. La única orientación formativa auténtica es la configuración de nuestras biopraxis educativas cotidianas, que nos permiten reconocer el carácter situado, histórico y cultural del aprendizaje y el conocimiento, su carácter contingente, ecológico, holístico, dialéctico, sistémico y configurativo. Las dicotomías y dualismos han sido muy nocivos en la historia de la humanidad y la ciencia: interno - externo, subjetivo - objetivo, mente - cuerpo, biológico - cultural, sujeto - objeto, cualitativo - cuantitativo, izquierda - derecha, ciudad - campo, afectivo - cognitivo, urbano - rural, emocional - racional. En fin, todas las dicotomías y dualismos fragmentadores limitan la comprensión del mundo natural-bio-neuro-psico-sociocultural.

A partir de la reflexión realizada anteriormente, pensamos que el proceso educativo decolonial no debe guiarse por una pedagogía, una didáctica o estrategias pedagógicas. Hablar de una didáctica decolonial es contradictorio en sus propios términos, por cuanto toda didáctica es colonizadora. Cuando utilizamos la noción de didáctica "otra" nos referimos a un tipo de proceso formativo diferente, cuya esencia es la decolonialidad holística, pero no es un método de enseñanza, no es una estrategia pedagógica estructurada por etapas, fases, momentos o pasos. El proceso formativo decolonizante se configura mediante acciones y huellas decoloniales.

No debemos hablar de didáctica decolonial, pero sí podemos referirnos a los criterios o actividades invariantes de un proceso formativo decolonizante, es decir, a las configuraciones de acciones decoloniales que implican un contemplar comunal, un conversar alterativo y un reflexionar configurativo. Las huellas formativas decoloniales son los rastros o vestigios que 
caracterizan las dinámicas educativas decoloniales, son todas aquellas acciones educativas decolonizantes que van dejando marcas y estampas durante el proceso formativo decolonial, materializadas por medio de las configuraciones praxiológicas decolonizantes, las cuales caracterizan el hacer educativo decolonial como proceso formativo decolonizante.

Hemos configurado estas reflexiones decolonizantes desde las urgencias y emergencias, para la resistencia, a partir de la desobediencia. Observamos una clara contradicción al utilizar la palabra didáctica en propuestas decoloniales. Si es didáctica entonces no es decolonial, porque toda didáctica tiene rasgos colonizadores. Argumentamos que la didáctica en sí misma es un elemento dominador, por ende, no debemos continuar utilizando el término didáctica porque "domina" y "aliena" a la decolonialidad. Por ello, introducimos la noción de proceso formativo decolonizante, que se configura desde el hacer educativo decolonial, mediante huellas y acciones decoloniales concretas.

El propio término "profesor" es colonizante, y también coloniza su posición dentro del proceso. Más que profesor, en realidad en el tránsito hacia la decolonialidad holística lo que necesitamos es un actor/mediador decolonial, una persona amorosa, reflexiva, con un alto grado de desarrollo de su pensamiento configuracional. El actor/mediador decolonial, más que profesor, es partícipe de ese proceso.

En la decolonialidad, la didáctica no se aplica trnasmitiendo nuevos conocimientos, aquí la didáctica se configura a partir de la visibilización de conocimientos "otros" existentes, válidos, argumentados, sentidos y vividos. Se hace con un sentido de convergencia y de resoluciones afectivas, dinámicas que tengan en cuenta al "otro", sus ideales, costumbres y acciones; sin la mínima aparición de conflictos producto del envanecimiento pedagógico, por creer que tenemos la verdad absoluta y poseemos un cono- cimiento universal y único.

Las pedagogías críticas y las didácticas participativas son los puntos detonantes del proceso reflexivo-decolonial, es decir, constituyen la génesis de la huella educativa decolonial. No podemos descalificarlas, más bien validarlas y darles sentido y significado dentro de la decolonialidad. No debemos subestimar o atacar, debemos valorar lo otro para validar y visibilizar lo "mío", debemos hablar y actuar en función de lo "nuestro", lo "propio". No obstante, en estas pedagogías y didácticas, el profesor, sin quererlo y sin saberlo, se convirtió en colonizador, no supo ir más allá de la frontera establecida por él mismo, es decir, no pudo develar su configuración teleológica decolonial y, como consecuencia de ello, tanto las estrategias, como los estilos, métodos y técnicas fueron insuficientes para la decolonialidad educativa holística.

Lo que intentamos conceptualizar como "proceso formativo decolonizante", en realidad es un proceso afectivo-reflexivo-configurativo-comprensivo, por cuanto decolonizar la didáctica implica "amar", "reflexionar", "cooperar", "comprender", contribuir en/con/por/para la propia comunidad estudiantil. Todo proceso formativo decolonizante es una autorreflexión configurativa. $Y$ todo actor/mediador decolonial debe dejar ver o visibilizar su posición política e ideológica.

Cuestionamos la formación y la enseñanza, tal como la conocemos hoy. Estamos de acuerdo que debemos formar y enseñar, pero colectivamente, con grupos comunes y diversos, formarnos y enseñar-nos entre todos, co-formarnos, co-enseñar, porque si forma y enseña solamente el "profesor", entonces deviene en colonizador. Esto permitirá un enlace con el "otro", buscando resultados que perpetúen las opciones liberadoras y emancipatorias de la subyugación de un sistema educativo que ha configurado estructuras y patrones dominantes para colonizar una generación productora de conocimientos "otros". 
Para que la pedagogía y la didáctica no sean colonizadoras, el actor decolonial debe incluir a los estudiantes en el proceso reflexivo-configuracional-comprensivo-decolonizante. Para poder conversar sobre algo, hay que observarlo a través de sus ojos, de sus pensamientos, y se le asigna sentido y significado a lo que observa, al compartirlo y conversarlo con el otro-yo. El observador decolonial no puede dejar de ver, es un observar comunal, comprensivo, reflexivo, que incluye al otro y le permite que de igual forma observe las biopraxis del actor decolonial, para que pueda ofrecer del mismo modo su reflexión configurativa y generar un diálogo comprensivo e incluyente.

El desarrollo de un proceso formativo decolonizante exige que una de las acciones imprescindibles sea la decolonialidad del ser, porque cuando el ser esta integralmente configurado en la decolonialidad, el producto de sus pensamientos lo llevan a reflexiones y a argumentos que le permiten generar procesos decoloniales. Todo tiene su génesis en el ser. Mediante éste configuramos, representamos y/o comunicamos nuestro sentir a otros. Primero vivimos, luego somos y hablamos, enseñamos, comunicamos, y posteriormente se generan las conversaciones, reflexiones y argumentos. No se trata quizá del olvido del ser por parte de la metafísica, sino como dijera Enrique Leff, el gran olvido de la metafisica occidental fue el olvido de la vida, ya que ella está antes que la ontología y del lenguaje como la casa del ser.

Esta mirada nos permite formular preguntas reflexivas, cuyas respuestas caracterizan un proceso formativo decolonial:

¿Qué necesitamos amar-reflexionar-configurarcomprender?

¿Para qué hacemos esta reflexión-configuración-comprensión?

¿Qué diferencia hará?
¿Quién desarrollará el proceso formativo decolonizante?

¿Cómo queremos hacer el proceso formativo decolonizante?

¿Cómo sabemos que vale la pena llevarlo a cabo y que es útil para la comunidad educativa?

¿Qué aportará este proceso afectivo-reflexivoconfiguracional?

¿Quiénes nos beneficiaremos, cómo y con qué?

Lo decolonial en el proceso educativo no puede reducirse a una didáctica o a una estrategia pedagógica, lo decolonial es mucho más que un método y un conjunto de técnicas y procedimientos para enseñar y aprender; más bien son acciones y huellas decoloniales.

Debemos desprendernos, como dice Mignolo (2013), no solo de los contenidos de los términos, sino de los propios términos, debemos crear nuevas configuraciones conceptuales comprensivas. Debemos desprendernos de las nociones de Pedagogía y de Didáctica, debemos configurar nuevos términos decoloniales.

El proceso que desplegamos es reflexivo-configurativo-decolonizante, es un hacer educativo decolonial, a partir del contemplar comunal, el conversar alterativo y el reflexionar configurativo. Más adelante intentamos matizar un poco sobre estos tres procesos en términos praxeológicos para las nuevas "ciencias" de la eduación del futuro. Pero ¿en qué se diferencia el hacer educativo decolonial de otras actividades y procesos que realizamos en nuestras biopraxis pedagógicas?, ¿debemos cambiar también el término pedagogía?, y si no es pedagogía, ¿qué es? Siempre hemos pensado que los profesores no formamos ni enseñamos, en realidad lo que hacemos es culturalizar, no es didáctica, es cultura. Entonces, ¿es cultura decolonial?

Para nosotros resulta claro que no se trata de 
una didáctica decolonial, no se trata de una pedagogía decolonial, tampoco es una antipedagogía ni una no-didáctica. Es un hacer educativo decolonial, representado en la cultura decolonizante, que se manifiesta por medio de tres acciones/criterios/condiciones/principios/ huellas: contemplar comunal, conversar alterativo y reflexionar configurativo.

El hacer educativo decolonial está configurado por las prácticas decoloniales. No es una pedagogía decolonial o una didáctica decolonial, en el sentido etimológico de "Yo cuido", "Yo enseño", porque entonces el profesor coloniza al estudiante. Las prácticas decoloniales llevan a configurar y reflexionar sobre conocimientos "otros" y formas "otras" de aprender y educar-se, que hacen válido el hacer "otro", en función de configurar un poder "otro" 6 . Este proceso formativo decolonizante es incluyente y genera participación, es un hacer. El hacer en conjunto, en grupo, en colectivo, es decir, un hacer educativo decolonial.

El hacer educativo decolonial no es pedagogía y tampoco es didáctica. ¿Es ciencia? Y si no es pedagogía ni didáctica, entonces ¿qué validez científica tiene? Hemos dado pasos firmes hacia el desprendimiento epistémico y epistemológico, al desengancharnos de las nociones de epistemología y metodología, pero no nos hemos desprendido aún de la noción de pedagogía y didáctica. Nos cuesta mucho trabajo dejar de usarlas. El hacer educativo decolonial es un conocimiento y una práctica que generan estilos "otros" y conocimientos "otros" que a su vez son producto de la metarreflexión de la realidad educativa propia en un contexto determinado. Es decir, podríamos considerarlo ciencia, pero desde una perspectiva diferente, incluyente, pero igualmente válida para la sociedad, porque en última instancia, es la reflexión y los resultados de ésta lo que arroja un conocimiento que es útil y tiene validez praxeológica. Podríamos 6 Recordemos que no hay justicia social sin justicia cognitiva (Santos, 2010). El poder se sustenta en el saber y deviene de éste. denominarlo ciencia "otra". Pero si es una ciencia "otra", entonces ¿por qué no puede llamarse pedagogía "otra" o didáctica "otra"?

Utilizando una metáfora, podríamos decir que son como dos líneas paralelas. Esencialmente son líneas, pero sus direcciones nunca se encuentran. Así ocurre con la decolonialidad educativa en tanto ciencia de la educación, aunque estamos más tentados en llamarle Cultura Educacional. Sea ciencia o sea cultura, existe, pero no se entrecruza con la ciencia clásica tradicional y dominante. La decolonialidad educativa se autoconfigura al margen de la ciencia pedagógica convencional, en los bordes, en la frontera. La decolonialidad educativa es una "ciencia"/ cultura fronteriza, indisciplinada y desobediente. Es una cultura educacional propia, que vive en los bordes fronterizos y se autoconfigura en/ desde/por/para su propia realidad educativa, la cual le permite desobedecer a la didáctica, a través de un hacer educativo decolonial.

\section{HACER EDUCATIVO DECOLONIAL: DESOBEDECER A LA DIDÁCTICA}

La pedagogía crítica y la didáctica participativa son prácticas neocoloniales, USA-eurocéntricas y occidentalizadas. En la primera mitad del siglo XX no era visible la colonialidad. Hoy sí. A partir del Giro Decolonial, existen hallazgos conceptuales interesantes en la década de los 90 y en el siglo XXI. Nuestro querido y respetado Pablo Freire, así como los precursores de la pedagogía crítica, no vieron la colonialidad del saber que subyace las nociones y prácticas pedagógicas. Por eso siguieron usando las nociones coloniales (pedagogía, didáctica, estrategia pedagógica). La doctrinalidad es la cara oculta de la formación y la pedagogía. La colonialidad de la enseñanza es la cara oculta de la didáctica. Por eso emerge el hacer educativo decolonial, no como pedagogía, ni como didáctica, ni estrategia pedagógica, sino como vocación, como configuración de acciones/huellas decolonizantes. Urge llevar aun más lejos las 
elaboraciones de Freire y la pedagogía crítica latinoamericana.

Es evidente que no es lo mismo hablar de didáctica desde la óptica del profesor y colonizador, que hablar de didáctica desde la mirada del estudiante y colonizado. Toda didáctica es colonizante. Todo profesor es colonizador. Desde la perspectiva del colonizado, la palabra didáctica es probablemente una de las palabras más excluyentes y dominantes en el vocabulario pedagógico. La didáctica se assume en/desde Abya Yala como un proceso deshumanizante, un conjunto de acciones de enseñanza colonizantes que causan dolor y sufrimiento a los estudiantes. Por eso las categorías y nociones son tan importantes. No es lo mismo decir "didáctica" que decir "hacer educativo decolonial", no es lo mismo decir "estrategias pedagógicas, métodos y ténicas de enseñanza" que decir "acciones/huellas decoloniales", no es lo mismo decir "profesor" que decir "mediador decolonial"; el concepto importa, los términos pueden ser modernos/ coloniales o pueden ser nociones decoloniales. Como afirma Grosfoguel (2007), el primer paso para descolonizar es nombrar. Es esencial identificar con categorías que hagan visible nuestro sentir-pensar.

Según Vázquez y Mignolo (2013), cada uno de los conceptos modernos/coloniales (estética, progreso, capitalismo, derechos humanos, educación, democracia, teoría, política, arte, cultura, género [y agregaríamos: pedagogía, currículo, didáctica, estrategia pedagógica, profesor, estudiante]) requiere un trabajo decolonial que implica: "1) Mostrar su genealogía en la modernidad occidental que nos permite transformar las afirmaciones de validez universal de los conceptos occidentales y convertirlos en conceptos históricamente situados; 2) Para mostrar su coIonialidad [así es como han funcionado para borrar, silenciar, denigrar otras formas de entender y relacionarse con el mundo]; y finalmente 3 ) Construir sobre esta base la opción decolonial, como un espacio no normativo, como un espacio abierto a la pluralidad de alternativas. En mi opinión, estos tres pasos son los tres momentos de lo que podemos llamar un método decolonial." (p. 6).

Estamos de acuerdo con Vázquez y Mignolo (2013), sobre la necesidad de realizar un trabajo decolonial con las nociones occidentales moderno/coloniales, e intentar cambiar no sólo el contenido de los términos sino los propios términos, tratando de crear nuevos conceptos decoloniales, siempre que sea posible y necesario, o usar los conceptos originarios desde la cosmovisión y formulaciones quechua, aymara, árabe y de otro tipo. Sin embargo, en lo que no podemos estar de acuerdo con estos autores es en el nombramiento, identificación y descripción de "pasos" o "momentos" de lo que ellos denominan "método decolonial", ya que esta categoría es tautológica, es una contradicción en sus propios términos; o sea, una autocontradicción, ya que si es un método no puede ser decolonial, por cuanto todo método es colonizante. Vázquez y Mignolo (2013) incurren en posiciones neocoloniales al realizar un trabajo semiótico decolonial mediante un método, es decir, el mismo hecho de proponer un método decolonial es un acto colonizante, o sea, que en la propuesta de estos autores subyace la colonialidad epistémica, de ahí que practican [quizá sin percatarse de ello] una decolonialidad colonial, y en este sentido incurren en lo que hemos denominado: Autocolonialidad $^{7}$. En fin, el sentipensar ${ }^{8} \mathrm{y}$ hacer educativo decolonial no implica deconstruir sino reconfigurar y decolonizar los conceptos clave de la modernidad, con el fin de mostrar su colo-

7 Ver: Ortiz, Alexander., Arias, María. Isabel. y Pedrozo, Zaira. (2018). Decolonialidad de la Educación. Urgencial emergencia de una Pedagogía Decolonial. Santa Marta: Universidad del Magdalena.

8 Con el neologismo "sentipensar", Moraes y Torre (2002) expresan el proceso mediante el cual se configuran pensamiento y sentimiento, dos formas de interpretar la realidad, mediante la reflexión y la emocionalidad, hasta converger en un mismo acto de conocimiento y acción. Con el término "sentipensar", se ilustra el cambio de paradigma en la ciencia. 
nialidad oculta y su alcance particular, situado, histórico y regional. Pero este proceso formativo decolonizante no se realiza mediante un método sino mediante acciones/huellas decoloniales que configuran -y se configuran en/desde/por/ para- el sentir-pensar-hacer humano.

Consideramos que el proceso educativo decoIonial no debe guiarse por una didáctica, hablar de una didáctica decolonial es contradictorio en sus propios términos, por cuanto toda didáctica es colonizadora.

Debemos desprendernos, como dice Mignolo (2013), no solo de los contenidos de los términos, sino de los propios términos, debemos crear nuevas configuraciones conceptuales comprensivas. Hemos dado pasos firmes hacia la desobediencia al desengancharnos de las nociones de pedagogía, didáctica y estrategia pedagógica.

En los procesos educativos, pensamos que no solo es el "profesor" quien debe formar y enseñar. Esto lo convierte en un colonizador pedagógico. El "profesor" no debe utilizar didácticas, ni estrategias pedagógicas, ni métodos de enseñanza. Más aún, el "profesor" no debe ser un profesor sino un actor, un facilitador de procesos liberadores, un mediador decolonial. La didáctica en sí misma es un elemento dominador, por ende, no debemos continuar utilizando el término didáctica porque "domina" y "aliena" a la decolonialidad. De ahí que introducimos la noción de proceso formativo decolonizante, que se configura desde el hacer educativo decolonial, mediante huellas y acciones decoloniales concretas. Lo decolonial en la educación no puede reducirse a una didáctica, lo decolonial es mucho más que una estrategia pedagógica y un conjunto de técnicas y procedimientos de enseñanza; más bien son acciones y huellas decoloniales.

Resulta claro que no se trata de una didáctica decolonial, tampoco es una anti-didáctica, ni una no-didáctica o didáctica indisciplinada. Estas didácticas "otras" nos dejan sin un nombre. Necesitamos el nombre de lo que somos y hacemos los "profesores" mediadores decoloniales. Hay que construir la palabra desde otras formas de mirar y de sentir. De ahí que utilizamos el Hacer Educativo Decolonial, que se concreta en acciones/huellas decoloniales (no en modelos pedagógicos, ni concepciones didácticas, ni estrategias pedagógicas). Estas acciones decoloniales de aprendiaje son: contemplar comunal, conversar alterativo y reflexionar configurativo.

Estas acciones decoloniales de aprendizaje forman parte del desprendimiento y desenganche de la didáctica occidental/eurocéntrica/colonial, para no seguirle el juego nocivo a la retórica de la pedagogía, sino apartarnos de la lógica de la colonialidad educativa, usando una gramática propia de la decolonialidad de la educación. Es decir, se trata de pensar con nuestras propias nociones y no importar categorías eurocentradas.

En la actualidad ya se agotaron las pedagogías críticas, los enfoques y modelos pedagógicos universales y las didácticas USA-eurocéntricas. Hoy emergen formas "otras" de educar, y ya está en marcha la pluriversalidad como proyecto educativo alternativo y alterativo de desprendimiento pedagógico. Esto indica que estamos ante la puerta de una crisis civilizatoria en la educación. Occidente como Paradigma Educativo hegemónico está en crisis. La noción de crisis civilizatoria es muy importante porque con ella enfatizamos que se está agotando el modelo occidental de educación. No obstante, Rivera-Cusicanqui (2010) advierte que toda teoría/discurso de la descolonización debe conllevar a una práctica descolonizadora. Es decir, un proyecto descolonizador no se puede quedar en el texto ni en el ámbito académico, sino que debe constituirse en una praxis que tienda hacia la descolonización (Vázquez, 2013). A esta praxis decolonizante le hemos denominado Hacer 
Educativo Decolonial, y se despliega mediante tres acciones/huellas decoloniales de aprendizaje: contemplar comunal, conversar alterativo y reflexionar configurativo, las cuales caracterizan la vocación educativa decolonial.

\section{ACCIONES/HUELLAS DECOLONIALES DE APRENDIZAJE: CONTEMPLAR COMUNAL, CONVERSAR ALTERATIVO Y REFLEXIONAR CONFIGURATIVO}

Cuando alguien se preocupa mucho por ofrecer y aplicar un modelo pedagógico, un enfoque didáctico, una estrategia pedagógica o un método de enseñanza, está actuando desde la modernidad y está siendo arrastrado por su cara oculta: la colonialidad. Para configurar un hacer educativo decolonial mediante un proceso formativo decolonizante, no podemos aplicar modelos, enfoques, estrategias, métodos, ni técnicas; solo considerar acciones/ huellas decoloniales de aprendizaje, más no son estrategias pedagógicas ni técnicas de enseñanza. Quien asuma la colonialidad como la cara ocultad de la modernidad, está obligado a abandonar la modernidad si no quiere sumergirse en la colonialidad. Tiene que cambiar los términos del discurso de la modernidad y no sólo su contenido, porque si no lo hace entonces configura un discurso moderno/colonial, o neocolonial.

Tenemos mucho que pensar, porque si la colonialidad es la cara oculta de la modernidad, y la decolonialidad no elimina totalmente la colonialidad, entonces tampoco elimina totalmente la modernidad. Y si somos modernos vivimos en colonialidad porque es su cara oculta. ¿Entonces? ¿Cómo reemplazar la modernidad colonizante que en el lenguaje coloniza nuestros pensamientos, acciones y sentires? ¿Cómo desprendernos del lenguaje sin causar trastornos de pensamiento? ¿Cómo desprendernos totalmente de la colonialidad? Pues debemos irnos a los bordes, ser exterioridad, vivir en la frontera, experienciar y vivenciar en/desde los bordes.

Las vivencias y experiencias son las configuraciones biopráxicas de acciones emocionales, cognitivas, intelectuales, axiológicas, actitudinales y praxiológicas. Es decir, son las huellas que configuran el sentir, pensar, conocer, aprender, saber, ser, hacer y vivir humanos. Las vivencias formativas decoloniales permiten configurar formas "otras" de educar, enseñar y evaluar. Mediante ellas decolonizamos las ciencias de la educación. Mediante ellas, configuramos un pensamiento alterativo, a partir de la decolonialidad de la educación, en función de con-vivires comunales.

\section{CONTEMPLAR COMUNAL}

El contemplar comunal puede ser definido como un momento de regreso, en el sentido que Kristeva (2004) le da al término, por cuanto el mediador decolonial vive la emocionalidad, la disfruta, observa la acción del otro, lo observa/escucha/ configura sin juzgar, lo siente y se deja sentir, deja salir su afectividad, se involucra con el otro, se deja llevar por su dinámica relacional, por su lógica discursiva, por sus anhelos, miedos, sueños y expectativas. Es un sentir-escucharvivenciar-observar decolonial, un escucharpercibir-observar colectivo, en el que el mediador decolonial no es el único que contempla, sino que se deja observar, observando. Es un contemplar cooperativo, dónde todos y cada uno de los actores decoloniales contempla al otro y se contempla a sí mismo. Es un contemplar emotivo-colaborativo, es decir un co-contemplar, un ponerse delante de......; un observar al otro/a, pero poniéndonos delante de él/ella para que también nos observe.

El contemplar comunal es un contemplar emotivo, porque no solo el mediador decolonial observa a los demás, sino que cada uno de ellos observa al mediador y observa a los demás, sin guías previas. Esto es una observación 
inversa, una observación decolonial. No es solo el mediador observando a todos, sino ellos observando al mediador y observándose unos a otros. El "profesor" es "estudiante". No es el "profesor" observando, analizando e interpretando lo que hacen los estudiantes, «los otros». Es el mediador con ellos y ellos con el mediador, juntos, observándose-escuchándosesintiéndose mutuamente, desde todas las miradas-escuchas-sentires, en clave decolonial, conversando afectivamente, tejiendo dialogares, teniendo en cuenta los conocimientos «otros», conocimientos situados, conocimientos válidos, potenciando el diálogo de saberes, entre iguales, configurando sofías decoloniales a partir del conversar alterativo y del reflexionar configurativo.

Con esta acción de aprendizaje, se desea comprender y expresar, a partir de las biopraxis de quienes se contemplan, sus intenciones, y quiénes les contemplan, asumir una postura frente a lo visto-escuchado-sentido, para poder utilizar la visión decolonial y poder visibilizar el accionar "otro" para darle sentido a todo el sistema y entorno. La contemplación-emotiva es incluyente porque permite que el mediador decolonial actúe, facilite, se exprese, y reconozca su rol, pero también el rol de la otra persona durante este proceso formativo decolonial.

Finalmente el contemplar comunal se relaciona como un sistema con el conversar alterativo y el reflexionar configurativo, ya que no se puede conversar sobre algún fenómeno o situación sin que antes sea contemplado de manera emotive. Además, este sistema tiene la particularidad de no tener un orden específico, realizándose de manera comprensiva e incluyente, en donde no se ignora a quienes son actores activos del proceso formativo decolonizante, y que no busca convertirse en algo autoritario para otros procesos de formación, ya que cada comunidad posee realidades educativas distintivas que le caracterizan.

\section{CONVERSAR ALTERATIVO}

Las pedagogías críticas y las didácticas participativas han situado, desde mediados del siglo pasado, la primacía de la comunicación, las relaciones dialógicas, el lenguaje, la conversación y la transformación. No obstante, estas teorías formativas y de la enseñanza no constituyen un valioso recurso educativo en el context de Abya-Yala, ya que no son conscientes del factor colonial, no tienen en cuenta la colonialidad pedagógica y curricular. El hacer educativo decolonial es más potente y fecundo si descansa en una conversación que tiene en cuenta la colonialidad, lo cual no hace la pedagogía crítica, ni sus didácticas participativas.

Las pedagogías críticas y las didácticas participativas no dan respuesta a las necesidades del estudiante, como ser subalterno y colonizado, por ello es necesario que surjan otras acciones decoloniales de aprendizaje, desde la reafirmación de nuestras identidades. Los dialogares decoloniales se manifiestan, evidencian y materializan a través del conversar alterativo, que se convierte en una condición sine cua non para la estabilidad y armonía en las relaciones humanas. Los dialogares decoloniales son representados por el conversar alterativo, afectivo y reflexivo, sin supuestos, sin expectativas, sin aprioris, sin condiciones, permitiendo que «el otro» también pregunte y exprese sus emociones, juicios y valoraciones. Es un dialogar respetuoso y solidario, con afecto, entre iguales. Los dialogares decoloniales no son una acción de enseñanza, en la que una cultura predomina sobre la otra, es un conversar espontáneo y fluido, emergente. Tampoco es un grupo de debate entre culturas, es un conversar que deviene en colectivo emergente de aprendizaje. Los dialogares decoloniales constituyen una configuración holística de discursos diversos, en los que se entrelazan de manera dialéctica 
saberes «otros», conocimientos válidos situados que representan la identidad cultural. De ahí que, no es posible hoy desarrollar procesos formativos al margen de los dialogares decoloniales. La didáctica moderna no propicia el conversar y no nos permite transformarnos por medio de la conversación. La armonía y coherencia tan necesaria en las relaciones humanas se configura mediante el conversar alterativo. Por otro lado, el fundamento de lo humano que caracteriza a "profesores" y "estudiantes" es el resultado del entretejido de los dialogares decoloniales que estos desarrollan. Por lo tanto, los dialogares decoloniales son la base y cimiento para la configuración de lo humano como cualidad distintiva de los actores decoloniales. Finalmente, los dialogares decoloniales constituyen la urgencia/ emergencia para la configuración de lo humano como principio ineludible del vivir en plenitud en el planeta Tierra.

El hacer educativo decolonial es una configuración práxico-afectiva y dialéctica de polos sintientes y pensantes, es un escenario en el que dos o más sujetos reflexionan sobre la visión que cada uno tiene del otro y sobre la experiencia vivida, lo cual permite generar un pacto de confianza que configura narrativas emocionales para transformar las vivencias y develar su sentido y significado, generando así otras lógicas formativas.

Debemos evitar la violencia de un método de enseñanza o estrategia pedagógica, debemos realizar procesos conversacionales, ya que la realidad y el mundo no es algo o un lugar que se descubre, sino una experiencia que se vivencia, se siente y se piensa, por lo tanto, constituye una relación social discursiva impregnada de poder. Esta posición aparentemente espontaneista puede preocupar, por el inconveniente de qué entender por conversación. Figari (2010) sugiere que debemos especificar las reglas del consenso y las condiciones de habla de los agentes, ya que una persona puede afirmar que está conversando, y otro asegurar que no es cierto (Butler, 2007).

No obstante, pensamos que el conversar alterativo presupone que ambos actores asumen que están conversando, ya sea para configurar conocimientos de manera intencional o simplemente para decolonizar, para vivir en comunalidad. Esto es el conversar alterativo: conversar para vivir, para vivir decolonialmente, por eso es alterativo, porque incluye al otro, lo cuida, lo protege, lo acoge, lo ama, conversa. Aunque callar también es comunicar, a veces el silencio es una maravillosa retórica y una gramática hermosa. Los humanos vivimos en el habla y en el silencio, ambos configuran el conversar. De ahí que el conversar alterativo sea una forma de vida, es la forma en que vivimos en comunalidad.

El conversar alterativo es una afluencia sígnica intersubjetiva que configura subjetividades entretejidas en una dinámica relacional. El conversar hace parte de las interacciones a través del lenguaje. El conversar alterativo implica versar con......, en el sentido de configurar versos junto con el otro, danzar juntos. El conversar alterativo no es una estrategia pedagógica, no es un método de enseñanza (en lugar de ser un camino que nos conduce al aprendizaje y al conocimiento, es ya un lugar de aprendizaje y conocimiento, una acción/huella decolonial de aprendizaje). En el conversar alterativo se fraguan las configuraciones conceptuales comprensivas, las sofías - aprendizajes - conocimientos "otros"- que configuramos entre todos, no sólo el mediador decolonial, sino también los demás actores del proceso formativo decolonizante. Con esta acción, se desea generar interacción con quienes se conversa, es decir, no hay imposiciones, solo se propone una situación problémica o un tema de concertación y se respeta la forma como el interlocutor lo aborda, no existen restricciones en cuanto a lo que exprese la persona o personas. 
El mediador decolonial conversa afectivamente con un estudiante, luego con otro y luego con otro más, hasta crear un grupo de reflexión, espontáneamente, sin supuestos, sin expectativas, sin aprioris, sin condiciones, permitiendo que los estudiantes también pregunten. Es un dialogar respetuoso y solidario, con afecto, entre iguales, sin que el mediador decolonial sea la única persona que pregunte. No es una transmision de conocimientos, es un conversar espontáneo y fluido, un colectivo emergente de aprendizaje. En una línea de pensamiento similar, Maturana (2003) considera que el presente se puede cambiar por medio del lenguaje, del diálogo respetuoso y fraterno, relacionar el vivir con el entrelazar tanto del lenguajear y el emocionar, el cual lo denomina el conversar.

Un conversar sin jerarquías pedagógicas le abrirá paso a una constante reflexión del quehacer educativo del mediador decolonial, autocuestionamientos y formas "otras" del enseñar, aprender, conocer y evaluar, permitiendo que ellos también pregunten, dialoguen solidariamente sin pretensiones de intereses informativos, que conversen entre todos, no como algo ya estructurado, sino como un diálogo de saberes entre iguales, compartiendo y llevando alternativas de cambio por medio de un reflexionar en conjunto. La acción del aprender y transformar emerge del proceso del conversar y reflexionar.

\section{REFLEXIONAR CONFIGURATIVO}

Figari (2010) nos recuerda que un rasgo característico de la ciencia es su comunicabilidad, por lo tanto, debemos preguntarnos "cómo comunicamos la experiencia entre dos cuerpos (no entre sujeto y objeto)" (p. 8). En efecto, el mediador decolonial no debe solamente contemplar al $-y$ conversar con- el otro, sino que debe configurar un aprendizaej y un conocimiento decolonial que se desprenda del patrón moderno/colonial de poder. Esto se logra mediante el reflexionar configurativo, mediante el cual escribimos nuestro sentir-pensar configurado de manera comu- nal. Como dice Figari (2010), los cuerpos situados solo producen conocimiento político, arte, poiesis resultado de la operación experiencial y situacional, mediada por el signo que se configura y se representa en la obra como texto, de la cual no podemos salirnos, porque no existe nada fuera del texto (Derrida, 1998). De ahí que sea necesario reintroducir esa experiencia semiótica nuevamente en lo simbólico -lo tético(Kristeva 2004).

El reflexionar configurativo implica volver a flexionar, soltar creencias, cerrar los ojos y abrir las manos para soltar las creencias que nos paralizan. El reflexionar sobre el contemplar comunal y sobre el conversar alterativo, como parte de nuestras interacciones, nos deslinda de lo ya configurado, manejado y manipulado con el interés de obtener información para provecho particular, ir creando un discurso habitual, lleno de cultura, acontecimientos que describan el mundo que hemos ido configurando. Es un reflexionar limpio y puro, sin supuestos, sin aprioris y sin expectativas, reflexionar solo desde el propio reflexionar liberador, que es un reflexionar edificante. Este proceso de acciones decolonizantes de aprendizaje no es una guía de momentos, ni fases, es una configuración, un sistema de redes que se generan simultáneamente. Es una acción decolonizante que permite configurar el conversar alterativo con el contemplar comunal. Es una de las huellas significativas del hacer educativo decolonial. No solo reflexiona el mediador decolonial, sino que reflexionan todos los participantes del proceso formativo decolonizante. Cuestionan en qué medida su hacer cotidiano es decolonial o es colonial, contribuyendo así a reproducir el sistema capitalista/moderno/colonial; adoctrinando a los demás, sumergiéndolos en un abismo intelectual y emocional, subjetivizándolos y subalternizándolos. Problematizan sus propias prácticas, saberes y sentires. Es un reflexionar holístico, complejo, sistémico, que tiene en cuenta no sólo los eventos, situaciones 
y acontecimientos, sino sus relaciones e interconexiones. Aquí lo más importante no es la sustancia sino el proceso. No importa tanto el ente en cuanto a configuración ontológica sino las relaciones entre los procesos. Interesa la trama oculta que deben develar, la red de redes, el entrelazamiento de discursos que configura la cotidianidad, el entretejido lingüístico que deviene en realidad educativa, el texto configurado en las biopraxis educativas, la configuración sígnica subyacente. El resultado del reflexionar configurativo es la emergencia de prácticas formativas "otras", formas "otras" de educar, enseñar y evaluar.

\section{SIGAMOS DECOLONIZANDO LAS CIENCIAS DE LA EDUCACIÓN}

Ortiz, Arias y Pedrozo (2018) han venido insistiendo en la necesidad de decolonizar las ciencias de la educación y su pretensión de objetividad científica. Estos autores abordan la urgencia/emergencia de una Pedagogía Decolonial. En efecto, las ciencias de la educación no deben configurar un conocimiento científico objetivo. Todo pensamiento y todo conocimiento es una configuración conceptual, no podemos pensar sin configuraciones sígnicas. El ser humano es una configuración sígnica, un signo, la pedagogía y la didáctica también. Todo lo que el profesor dice, se lo dice a otra persona o a sí mismo. La descripción no es lo mismo que lo que se describe. El mapa no es el territorio. No podemos conocer "la cosa en sí". Solo conocemos las descripciones. Solo conocemos los mapas. La didáctica tiene un límite que es puesto por el lenguaje. Somos cautivos del significado.

La didáctica no debe analizarse de manera separada de la vida humana cotidiana. La vida es inicio (primeridad), la didáctica es fin (segundidad), y el pensamiento o reflexión es el mediador (terceridad) entre la vida y la didáctica. Vivir, conocer y aprender, son lo mismo, constituyen una configuración tríadica.
Es preciso detallar las condiciones o requisitos para comprender las formas "otras" emergentes de educar, enseñar y evaluar: asumir una actitud fenomenológica, poner entre paréntesis nuestras creencias, dar un salto conceptual, indisciplinar la didáctica, y sobre todo el desprendimiento y la desobediencia.

Todo proceso formativo decolonizante debe sustentarse en tres criterios invariantes: amar (contemplar comunal), reflexionar configurativo y conversar alterativo. Según Maturana (2003), la biología humana se sustenta en la emoción del amar (no del amor como sustantivo sino del amar como verbo, que expresa una acción). Es necesario entonces configurar una "ciencia"/ cultura del amar. Debemos configurar el contemplar comunal, el conversar alterativo y el reflexionar configurativo, como acciones inmanentes del hacer educativo decolonial.

Cuando el vivir de una persona no fluye en el amar es porque hay grietas y fisuras en la armonía y coherencia de la configuración de la personalidad, es decir, falencias en su educación, porque no hay verdadera educación sin amar, ya que la esencia constitutiva de los seres humanos al nacer es el amar.

No tiene sentido en una nación formar personas muy capaces, competentes, inteligentes, que no sepan amar. ¿Qué sentido tiene formar profesionales, magísteres y doctores que no sepan convivir con los demás? La principal cualidad que se debe conservar en el vivir humano y en su formación es la capacidad y compromiso de vivir en el amar.

La emoción determina la acción humana. No hay acción sin emoción. Son más de 600 emociones en las que podemos fluir los seres humanos. Una de ellas es el amar. Es la emoción mediante la cual aceptamos a los demás en el convivir cotidiano, como personas legítimas que merecen coexistir con nosotros, independientemente de su etnia, peso, tamaño, filiación política o religi- 
osa, género, orientación sexual, nacionalidad, música preferida, alimentos que consume, ropa que usa, o hinchada a la que pertenezca en los partidos de futbol.

En la actividad "pedagógica"/cultural, el amar se manifiesta cuando comprendemos a los actores del proceso formativo decolonizante, cuando los aceptamos en el espacio formativo, sin exigencias, sin condiciones, cuando somos respetuosos, honestos, comprensivos, solidarios y afectuosos con ellos. No podemos exigir lo que no damos, y no podemos dar lo que no poseemos. Entonces debemos reflexionar sobre lo que exigimos, lo que damos y lo que poseemos. Debemos ser coherentes. Ahora bien, para configurar un hacer educativo "otro" no basta con el amar, necesitamos además reflexionar. Realizar una reflexión sistémica, holística, que tenga en cuenta la complejidad del mundo educativo. Necesitamos practicar el reflexionar configurativo.

$83 \cdot$ El actor/mediador decolonial configura cultura propia, no forma, no enseña; visibiliza. El profesor coloniza, invisibiliza, subalterniza. Debemos pensar y reflexionar para no ser pensados. Si dejamos pensarnos, permitimos que nos subalternicen. Hemos dejado que otros piensen por nosotros. Somos una sociedad de lo instantáneo. Ya no conversamos. El conversar nos libera, nos configura, nos forma y transforma. Conversar es una palabra que viene del latín y significa "dar vueltas juntos". Debemos aprovechar el potencial del reflexionar configurativo. Es un reflexionar limpio y puro, sin supuestos, sin aprioris y sin expectativas, reflexionar solo desde el propio reflexionar liberador, que es un reflexionar edificante. El hacer educativo decolonial tiene que ser reflexivo. A las clases debemos ir a reflexionar.

En el reflexionar configuramos el mundo en que vivimos. Cada vez que una persona reflexiona tiene la posibilidad de volver a nacer, porque mediante los nuevos términos que utiliza y los nuevos contenidos de dichos términos, crea nuevas realidades. Esto no es trivial, para configurar una educación "otra" (hacer educativo decolonial) debemos configurar una nueva cultura, la cultura de la decolonialidad, pero ¿qué es cultura?, la cultura es una configuración de conversaciones, una trama o red de configuraciones lingüísticas. La cultura es un signo. Para configurar una cultura decolonial debemos comenzar a reflexionar sobre la decolonialidad y cómo cada uno de nosotros puede ser un educador decolonial, para luego entusiasmar, inspirar, encantar y acoger a los demás con nuestra decolonialidad, mediante el conversar alterativo.

El conversar alterativo no es una estrategia pedagógica, no es un método de enseñanza (en lugar de ser un camino que nos conduce al aprendizaje y al conocimiento, es ya un lugar de aprendizaje y conocimiento, una acción/huella decolonial de aprendizaje). En el conversar alterativo se fraguan las configuraciones conceptuales comprensivas, las sofías, conocimientos y aprendizajes "otros" que configuramos entre todos, no sólo el actor/mediador decolonial que contempla, sino también los demás actores del proceso formativo decolonizante, quienes también son contempladores comunales.

Debemos aprovechar el potencial del conversar alterativo y el reflexionar configurativo, sin supuestos, sin aprioris y sin expectativas, solo desde el propio conversar liberador y el reflexionar edificante. La única forma de decolonizar las ciencias de la educación es por medio de la decolonialidad holística, porque por nuestras venas transita la colonialidad del saber, el poder, el ser y el vivir. Es muy difícil configurar un hacer "otro" sin decolonizar el poder, el saber, el ser y el vivir. Y esto se logra mediante el conversar alterativo y la autodecolonialidad, entendida como el proceso mediante el cual nos autopurificamos, nos purificamos a nosotros mismos como actores y creadores decoloniales. Configuramos la decolonialidad. 
El conversar alterativo es un conversar libre y espontáneo, sin exigencias, sin condiciones, sin expectativas, que permite encontrarnos en la emoción del candor, en la aceptación, sin esperar algo a cambio de lo que expreso libremente, desde mi sentir y mi pensar. El conversar alterativo es un conversar sin aprioris y sin supuestos. $Y$ tiene que ser así porque cuando conversamos esperando que el otro sin reflexionar haga o asuma lo que nosotros decimos, entonces el conversar se convierte en un acto que perpetúa la colonialidad. De ahí la importancia, sentido y significado del amar, el contemplar comunal y el reflexionar configurativo, unidos al conversar alterativo, como criterios/principios/huellas/condiciones/acciones del proceso formativo decolonizante.

Los retos y desafíos de la "ciencia"/cultura decoIonial son, en primer lugar, propiciar el amar, el contemplar comunal, el reflexionar configurativo y el conversar alterativo en los procesos formativos decolonizantes. Los actores decoloniales debemos estimular y potenciar la capacidad de amar, contemplar, reflexionar y conversar (desde una perspectiva decolonial) en los actores que se entrelazan con nuestras biopraxis educativas. Pero para ello los actores decoloniales también debemos amar a los demás actores del hacer educativo decolonial, reflexionar de manera configurativa sobre nuestra labor "pedagógica"/cultural y conversar alterativamente y decolonialmente con ellos. Debemos continuar la ardua senda de la configuración de la teoría del hacer educativo decolonial y desarrollar sus tres acciones básicas de aprendizaje: contemplar comunal, conversar alterativo y reflexionar configurativo, que devienen en criterios/principios/ huellas educativas decoloniales.

Las "ciencias educacionales" decoloniales no deben centrarse solo en lo humano, no deben analizar solamente los conflictos sociales y las relaciones entre los seres humanos, deben formar parte de las ciencias de la vida o del vivir, porque la vida es una configuración humana y se desarrolla en sociedad. De ahí que las nuevas ciencias de la educación serían ciencias del Buen Vivir: justicia, equidad, libertad, paz, autodeterminación, solidaridad, en fin, decoIonialidad del vivir. Lo único que los seres humanos poseemos y de lo que podemos hablar ontológicamente es de la vida, por lo tanto, la configuración conceptual comprensiva de las nuevas ciencias educacionales es precisamente la vida humana, las biopraxis lingüísticas, los signos que configuran nuestra cotidianidad.

La razón moderna se configuró a partir de la relación medio-fines, esa racionalidad coincide con la forma y el fondo como se configuraron las teorías y organizaciones educativas. Dicho de otra manera, la forma de crear teorías educativas es concordante con la racionalidad moderna. El sistema educativo se estructura en esa lógica. Sin embargo, desde la opción decolonial, romper/desprenderse/desobedecer con/al sistema educativo tradicional implica tres planos: el altersófico, lo que implica establecer la relación equitativa y amorosa sujeto-sujeto, el conceptual que deriva de ello, y el biopráxico, que es lo que denominamos Hacer Educativo Decolonial.

Reiteramos la urgencia de decolonizar y desprendernos de las ciencias de la educación. Problematizamos y cuestionamos la pedagogía por enarbolar un conocimiento verdadero universal (episteme) centrado en el "profesor", privilegiando la relación sujeto-objeto, desconociendo el saber del "estudiante". Proponemos configurar una teoría educativa que se concentre en la relación sujeto-sujeto, es decir, entre un yo con otro yo, reconociendo y visibilizando el saber del otro colonizado y subalternizado, sus conocimientos situados (sofías). Emerge así la altersofía como una manera "otra" de formar. Es necesario crear formas "otras" de educar, enseñar y evaluar, lo cual requiere la configuración de nuevos tipos de conocimientos, nuevas formas de educar-se y aprender, y nuevas "cien- 
cias educacionales" cuya estructura categorial se sustente en el saber del Otro, considerado inferior, y no sólo en la pedagogía moderna/colonial, considerada superior.

En efecto, toda didáctica coloniza. Porque el "profesor" se visibiliza a sí mismo, usa una estrategia pedagógica o un método de enseñanza, con pasos que constituyen argumentos para obligar. El "profesor" observa y pregunta, pero no le permite observar ni preguntar al "estudiante". Se ve a sí mismo y excluye al Otro, lo niega y opaca con su voz. En cambio, en el proceso del hacer educativo decolonial se van dando las tres acciones sin pedir permiso, de forma natural y espontánea. De ahí que, hablar del reflexionar configurativo devela un entrelazamiento entre el conversar alterativo y el contemplar comunal. El mediador decolonial reflexiona como intermediario del proceso, y además todos reflexionan sobre sus saberes, formas de aprender, sentires y prácticas educativas.

\section{REFERENCIAS BIBLIOGRÁFICAS}

Arendt, Hannah. (2014/1971). La vida del espíritu. Barcelona: Paidós.

Butler, Judith. (2007). Géneros en disputa. EI feminismo y la subversión de la identidad, Buenos Aires: Paidós.

Denzin, Norman. (2003). Performance ethnography: Critical pedagogy and the politics of culture. Thousand Oaks, CA: Sage.

Derrida, Jackes. (1998/1967). De la Gramatología. México: Siglo XXI.

Escobar, Arturo. (2003). Mundos y conocimientos de otro modo: el programa de investigación de modernidad/colonialidad Latinoamericano. Tabula Rasa. (1): 5186.
Figari, Carlos. (2010). Conocimiento situado y técnicas amorosas de la ciencia. Tópicos de epistemología crítica. Mimeo.

Fox-Keller, Emili. (2000). Lenguaje y vida. Metáforas de la biología en el siglo XX. Buenos Aires: Manantial.

Freire, Paulo. (1994). Educación y participación comunitaria. En: Gastells, M. et. al. Nuevas perspectivas críticas en educación. Barcelona: Paidós.

Freire, Paulo. (1997). A la sombra de este árbol. Barcelona: El Roure.

Freire, Paulo. (2009/1992). Pedagogía de la Esperanza. México: Siglo XXI.

Freire, Paulo. (2011/1969). La educación como práctica de la libertad. Madrid: Siglo XXI.

Freire, Paulo. (2012a/1970). Pedagogía del Oprimido. Madrid: Siglo XXI.

Freire, Paulo. (2012b/1993). Cartas a quien pretende enseñar. México: Siglo XXI.

Freire, Paulo. (2013/1984). La importancia de leer y el proceso de liberación. México: Siglo XXI.

Freire, Paulo. (2014/1996). Pedagogía de la Autonomía. Saberes necesarios para la práctica educativa. México: Siglo XXI.

Grosfoguel, Ramón. (2007). Entrevista a Ramón Grosfoguel. Angélica Montes Montoya / Hugo Busso. Polis, Revista de la Universidad Bolivariana, No. 018, Universidad Bolivariana, Santiago, Chile.

Heidegger, Martín. (2012/1927). El ser y el tiempo. México: FCE.

Kristeva, Julia. (2004). Semiótica 1. Madrid: Fundamentos. 
Las Casas, Bartolomé de. (1942). Del único modo de atraer a todos los pueblos a la verdadera religión. México: FCE.

Levinas, Enmanuel. (2014/1995). Alteridad y trascendencia. Madrid: Fata Morgana.

Maldonado-Torres, Nelson. (2006). Césaire's Gift and the Decolonial Turn. Radical Philosophy Review, 9(2), pp. 111-137.

Maturana, Humberto. (2003). Desde la Biología a la Psicología. Buenos Aires: Lumen.

Mignolo, Walter. (2013/2000). Historias locales/ diseños globales. Colonialidad, conocimientos subalternos y pensamiento fronterizo. Madrid: Akal.

Moraes, Milton y Torre, Saturnino. de la. (2002). Sentipensar bajo la mirada autopoiética o cómo reencantar creativamente la educación. Revista Creatividad y Sociedad, No. 12, pp. 41-56.

Mutua, K., y Swadener, B. B. (2004). Introduction. In K. Mutua y B. B. Swadener (Eds.), Decolonizing research in crosscultural contexts: Critical personal narratives (pp. 1-23). Albany, NY: SUNY Press.

Ortiz, Alexander. (2013). Configuralogía. Paradigma epistemológico y metodológico en las Ciencias Humanas y Sociales. Barranquilla: Antillas.

Ortiz, Alexander y Arias, María. Isabel. (2018). Hacer decolonial: desobedecer a la metodología de la investigación. Hallazgos 2019, 16(31), 149-168. Doi: https://doi.org/10.15332/s17943841.2019.0031.06. ISSN: 1794-3841. e-ISSN: 2422-409X. https://revistas.usantotomas.edu.co/index.php/hallazgos/ issue/view/472

Ortiz, Alexander y Arias, María. Isabel. (2019).
Altersofía y Hacer Decolonial: epistemología 'otra' y formas 'otras' de conocer y amar, Revista Utopía y praxis latinoamericana. Año 24, $\mathrm{N}^{\circ} 85,2019$, pp. 89-116. ISSN 1316-5216 / ISSN-e: 2477-9555.

Ortiz, Alexander, Arias, María Isabel y Pedrozo, Zaira. (2018). Decolonialidad de la Educación. Urgencia/emergencia de una Pedagogía Decolonial. Santa Marta: Universidad del Magdalena.

Rivera-Cusicanqui, Silvia. (2010). Ch'ixinakax utxiwa: una reflexión sobre prácticas y discursos descolonizadores. 1a ed. Buenos Aires: Tinta Limón.

Santos, Boaventura de Souza. (2009). Una epistemología del sur: La reinvención del conocimiento y la emancipación social. CLACSO: Siglo XXI.

Semali, L. M., y Kincheloe, J. L. (1999). Introduction: What is indigenous knowledge and why should we study it? In L. M. Semali y J. L. Kincheloe (Eds.), What is indigenous knowledge? Volees from the academy (pp. 3-57). New York: Falmer.

Vázquez, Bertha. (2013). Educación decolonialliberadora. Perspectivas. Revista de Historia, Geografía, Arte y Cultura. Universidad Nacional Experimental Rafael María Baralt, Año $1 \mathrm{~N}^{\circ} 2$, Julio-diciembre, 2013, pp. 177-196

Vázquez, Rolando y Mignolo, Walter. (2013). AestheSis descolonial: heridas coloniales / curas descoloniales. https:// socialtextjournal.org/periscope_article/ decolonial-aesthesis-colonial-woundsdecolonial-healings/ 
Walsh, Catherine. (2002). "Las geopolíticas de conocimiento y colonialidad del poder. Entrevista a Walter Mignolo", en: Indisciplinar las ciencias de la educación, editado por Catherine Walsh, Freya Schiwy y Santiago Castro-Gómez, Quito: Abya Yala, UASB.

Walsh, Catherine. (2013). Pedagogías decoloniales. Prácticas insurgentes de resistir, (re)existir y (re)vivir. Tomo I. Quito: Abya-Yala.

Walsh, Catherine. (2014). Lo Pedagógico y lo Decolonial: Entretejiendo Caminos. Equipo de En Cortito que's pa' Largo. P. 4- 87. Querétaro. 